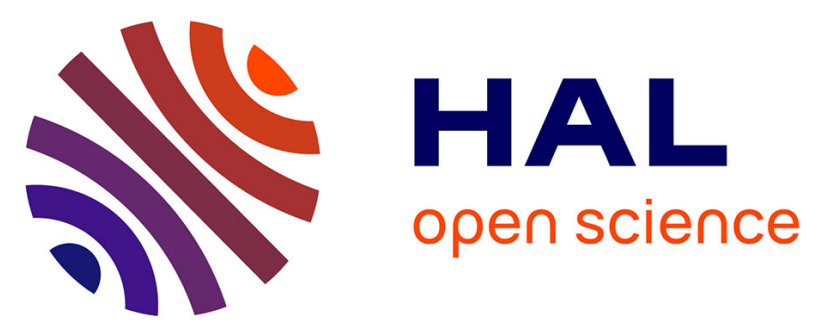

\title{
HAMSTRAD-Tropo, A 183-GHz Radiometer Dedicated to Sound Tropospheric Water Vapor Over Concordia Station, Antarctica
}

Philippe Ricaud, Benjamin Gabard, Solène Derrien, Jean-Pierre Chaboureau, Thomas Rose, Andreas Mombauer, Harald Czekala

\section{To cite this version:}

Philippe Ricaud, Benjamin Gabard, Solène Derrien, Jean-Pierre Chaboureau, Thomas Rose, et al.. HAMSTRAD-Tropo, A 183-GHz Radiometer Dedicated to Sound Tropospheric Water Vapor Over Concordia Station, Antarctica. IEEE Transactions on Geoscience and Remote Sensing, 2010, 48 (3), pp.1365-1380. 10.1109/TGRS.2009.2029345 . hal-00995290

\section{HAL Id: hal-00995290 \\ https://hal.science/hal-00995290}

Submitted on 28 Jan 2022

HAL is a multi-disciplinary open access archive for the deposit and dissemination of scientific research documents, whether they are published or not. The documents may come from teaching and research institutions in France or abroad, or from public or private research centers.
L'archive ouverte pluridisciplinaire HAL, est destinée au dépôt et à la diffusion de documents scientifiques de niveau recherche, publiés ou non, émanant des établissements d'enseignement et de recherche français ou étrangers, des laboratoires publics ou privés.

\section{(c) (1) $\$$}

Distributed under a Creative Commons Attribution - NonCommerciall 4.0 International 


\title{
HAMSTRAD-Tropo, A 183-GHz Radiometer Dedicated to Sound Tropospheric Water Vapor Over Concordia Station, Antarctica
}

\author{
Philippe Ricaud, Benjamin Gabard, Solène Derrien, Jean-Pierre Chaboureau, \\ Thomas Rose, Andreas Mombauer, and Harald Czekala
}

\begin{abstract}
The $\mathrm{H}_{2} \mathrm{O}$ Antarctica Microwave Stratospheric and Tropospheric Radiometers (HAMSTRAD) program aims to develop two ground-based microwave radiometers to sound tropospheric and stratospheric water vapor $\left(\mathrm{H}_{2} \mathrm{O}\right)$ above Dome $\mathrm{C}$ (Concordia Station), Antarctica $\left(75^{\circ} 06^{\prime} \mathrm{S}, 123^{\circ} 21^{\prime} \mathrm{E}, 3233 \mathrm{~m}\right.$ asml), an extremely cold and dry environment, over decades. By using state-of-the-art technology, the HAMSTRAD-Tropo radiometer uses spectral information in the domains 51-59 $\mathbf{G H z}$ (oxygen line) and 169-197 GHz (water vapor line) to derive accurate tropospheric profiles of temperature (with accuracy ranging from 1 to $2 \mathrm{~K}$ ) and low absolute humidity (with accuracy ranging from 0.02 to $0.05 \mathrm{~g} \cdot \mathrm{m}^{-3}$ ), together with integrated water vapor (with accuracy of about $0.008 \mathrm{~kg} \cdot \mathrm{m}^{-2}$ ) and liquid water path. Prior to its installation at Dome $\mathrm{C}$ in January 2009, the fully automated radiometer has been deployed at the Pic du Midi (PdM, $42^{\circ} 56^{\prime} \mathrm{N}, 0^{\circ} 08^{\prime} \mathrm{E}, 2877 \mathrm{~m}$ asml, France) in February 2008 and was in operation for five months. Preliminary comparisons with radio soundings particularly launched in the vicinity of PdM in February 2008 and the outputs from the mesoscale MESO-NH model show a great consistency to within $0.2-0.3 \mathrm{~g} \cdot \mathrm{m}^{-3}$ between all absolute humidity data sets whatever the atmosphere considered (extremely dry or wet).
\end{abstract}

Index Terms-Atmospheric measurements, humidity measurement, microwave measurements, microwave radiometry.

\section{INTRODUCTION}

$\mathbf{S}$ INCE the discovery of the ozone hole in the mid-1980s over Antarctica and the Montreal Protocol phasing out the production of freons, the main compounds that destroy the ozone layer, the international scientific community focused on the understanding of the photochemical processes acting in the middle atmosphere. Chemistry-climate interactions are far from being known and could modify even more the evolution of the ozone layer by favoring more stable and colder polar vortices, thus increasing the probability of occurrence of polar stratospheric clouds (PSCs), consequently increasing

P. Ricaud, S. Derrien, and J.-P. Chaboureau are with the Laboratoire d'Aérologie, Université de Toulouse, CNRS UMR 5560, 31400 Toulouse, France (e-mail: philippe.ricaud@ aero.obs-mip.fr).

B. Gabard is with the Office National d'Etudes et de Recherches Aérospatiales, 31400, Toulouse, France.

T. Rose, A. Mombauer, and H. Czekala are with Radiometer Physics GmbH, 53340 Meckenheim, Germany. chlorine activation, and slowing down the recovery of the ozone layer [1].

Water vapor $\left(\mathrm{H}_{2} \mathrm{O}\right)$ plays a key role in the Earth climate system since it is the main greenhouse gas emitting and absorbing in the infrared domain. Its variability in both the troposphere and the stratosphere is still an enigma or, at least, is still under discussion [2]. Indeed, neither the positive trend in methane (stratospheric source) nor the negative trend of the tropopause temperature (direct injection from the troposphere to the stratosphere) can explain the positive trend in stratospheric $\mathrm{H}_{2} \mathrm{O}$ measured up to 2000 and the negative trend since then. At high latitudes and more precisely over Antarctica in winter, the stratospheric polar vortex develops within a cold and dry atmosphere where physico-chemical processes are globally well known [3]: presence of PSC, dehydration, halogen activation (chlorine and bromine compounds) via heterogeneous chemical reactions and solar illumination, sedimentation, descent within the core of the vortex, and denitrification, all these processes producing ozone loss. Nevertheless, great uncertainties (differences between measurements and model) pertain or are linked to the quantification of the ozone loss rate, denitrification rate, descent rate, and dehydration rate within the polar vortex. Several campaigns have been organized by the European community in the Northern Hemisphere to understand the destruction mechanisms within polar vortices (see, e.g., [4]). These campaigns have not been taken place in the Southern Hemisphere so far.

The $\mathrm{H}_{2} \mathrm{O}$ Antarctica Microwave Stratospheric and Tropospheric Radiometers (HAMSTRAD) program aims to develop two ground-based microwave radiometers to sound tropospheric and stratospheric $\mathrm{H}_{2} \mathrm{O}$ above Dome $\mathrm{C}$ (Concordia Station), Antarctica $\left(75^{\circ} 06^{\prime} \mathrm{S}, 123^{\circ} 21^{\prime} \mathrm{E}, 3233 \mathrm{~m}\right.$ asml) over a long time period. HAMSTRAD-Tropo is a $183-\mathrm{GHz}$ radiometer for measuring tropospheric $\mathrm{H}_{2} \mathrm{O}$, subject to this paper. HAMSTRAD-Strato is a microwave radiometer for measuring stratospheric $\mathrm{H}_{2} \mathrm{O}$ that is still under study based upon the heritage of recently developed microwave instruments at $22 \mathrm{GHz}$ [5]. The HAMSTRAD radiometers will complement two other instruments: an ultraviolet-visible Système d'Analyse par Observation Zénithale instrument [6] for the measurements of ozone and nitrogen dioxide columns and detection of PSCs, and an ultraviolet (UV) photometer [7] to measure UVB radiation in the domain $280-320 \mathrm{~nm}$ at the surface. These instruments intend to give some elements of answer to important questions relative to the evolution of the ozone layer, to the constituents linked to its destruction, to dynamical processes coupled to the polar vortex evolution, 
and, consequently, to the chemistry-climate interactions. Being given that the lifetime of the Dome $\mathrm{C}$ station is expected to be about 40 years, these instruments are or will be fully automated, with a minimum of human interactions from the local manpower of the site, and will be in fine part of the international Network for the Detection of Atmospheric Composition Change (NDACC). The NDACC [8] is a network of state-ofthe-art research instruments for the long-term observation of the stratosphere and, very recently, of the upper troposphere.

The geographical situation of Dome $\mathrm{C}$ (high altitude and dry air) is particularly well adapted to the setting of other instruments for monitoring the stratosphere and the troposphere, for instance, the microwave radiometers. The altitude of the Dome C site associated with a weak amount of water vapor in the troposphere and very low temperatures encountered in the lowermost altitude layers (one of the driest and coldest site around the world) favors the setting-up of microwave radiometers at high frequency and with a much better sensitivity (weak integration time) with respect to sites located at sea level in order to detect both stratospheric and tropospheric water vapor. The latitude of Dome $\mathrm{C}\left(75^{\circ} \mathrm{S}\right)$ is also low enough to be part of the validation of scientific spaceborne sensors in quasi-polar orbits (inclination usually about $97^{\circ}$ ), e.g., for $\mathrm{H}_{2} \mathrm{O}$ : the Sub-Millimeter Radiometer instrument aboard the ODIN satellite [9], the Michelson Interferometer for Passive Atmospheric Sounder instrument aboard the ENVISAT platform [10], the Microwave Limb Sounder instrument aboard the AURA satellite [11], and the Infrared Atmospheric Sounder Interferometer instrument aboard the MetOp satellite [12]. Finally, the high latitude of the site might also help in validating the analyses of the European Centre for Medium-range Weather Forecast (ECMWF).

It is rather challenging to detect $\mathrm{H}_{2} \mathrm{O}$ lines with ground-based microwave radiometers installed at very cold and dry areas as they can be encountered at high elevation and/or high latitudes. The generally used $6_{16}-5_{23}$ transition line at $22.235 \mathrm{GHz}$ (see, e.g., [13] and [14]) has the main advantage to be detectable in the majority of sites around the world but has the main drawback to be rather weak to be measured in very dry and cold conditions as they can be encountered at high latitudes, for instance. Recently, some ground-based microwave radiometers have been set up to detect the $3_{13}-2_{20}$ transition line at $183.310 \mathrm{GHz}$ (see, e.g., [15] and [16]) to estimate the vertical distribution of tropospheric humidity. Within the Arctic Winter Experiment held at the Atmospheric Radiation Measurement program's North Slope of Alaska site near Barrow (Alaska, U.S.) in 2004 [17], the Ground-based Scanning Radiometer [18] measuring, among other transitions, the 183- $\mathrm{GHz} \mathrm{H}_{2} \mathrm{O}$ line was deployed in coincidence with some resident 22-GHz radiometers and some radio-sounding launches. Global results show that, in extremely dry conditions, the precipitable water vapor (ranging from 1 to $2 \mathrm{~mm}$ ) can be estimated within $5 \%$ uncertainty [19]. It is also demonstrated that the 183-GHz radiometer contains channels that receive a significant response from the upper tropospheric region [20], although the following are observed: 1) some daytime dry biases were detected in the radio soundings [21], and 2) stratospheric contribution might also be non-negligible when integrated water vapor (IWV) is less than $1 \mathrm{~mm} \mathrm{[20].}$

This paper focuses on the description of the HAMSTRADTropo instrument dedicated to sound tropospheric $\mathrm{H}_{2} \mathrm{O}$ over

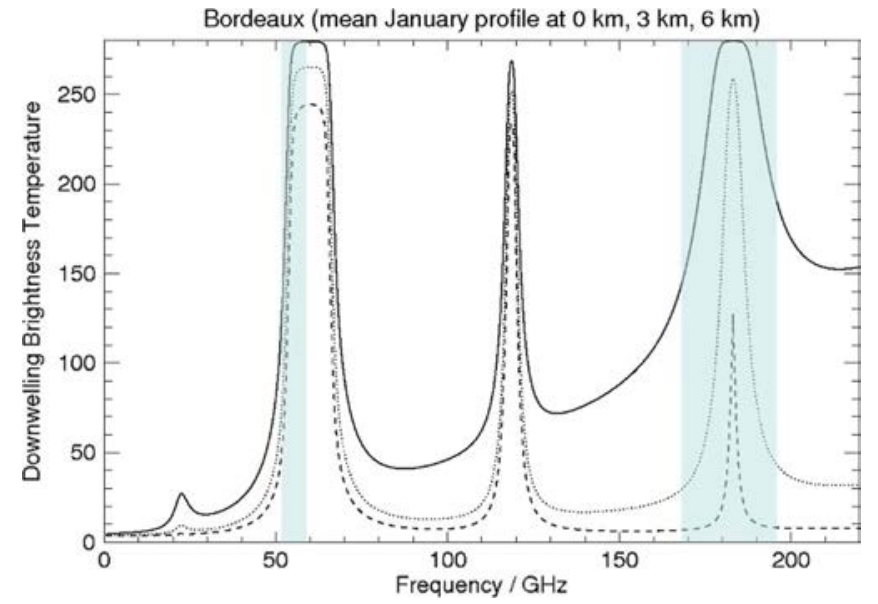

Fig. 1. Theoretical brightness temperature TB calculated for a downwelling radiation reaching (dashed line) the altitude of $6000 \mathrm{~m}$, (dotted line) altitude of $3000 \mathrm{~m}$, and (solid line) sea level from 0 to $220 \mathrm{GHz}$. The spectral domains of the HAMSTRAD-Tropo radiometer are 51-59 GHz for the $\mathrm{O}_{2}$ line and 169-197 GHz for the $\mathrm{H}_{2} \mathrm{O}$ line (light blue filled boxes).

Dome $\mathrm{C}$ and the first results of the validation phase performed at Pic du Midi (PdM, $42^{\circ} 56^{\prime} \mathrm{N}, 0^{\circ} 08^{\prime} \mathrm{E}, 2877 \mathrm{~m}$ asml, France) in February-June 2008 prior to its installation at Dome C in January 2009. Section II presents the theoretical background combining radiative transfer and retrieval studies to optimally set up the appropriate frequencies and discusses the estimated vertical resolutions and errors associated to the vertical profiles of temperature and $\mathrm{H}_{2} \mathrm{O}$ together with IWV and liquid water path (LWP). Section III describes the instrument characteristics together with the measurement and calibration procedures. The first measurements performed by HAMSTRAD-Tropo at PdM will be shown in Section IV. Preliminary validation of the measured $\mathrm{H}_{2} \mathrm{O}$ vertical profiles will be done in Section V by comparison with sondes launched on different sites (Bordeaux and Lannemezan in France, and Zaragoza in Spain) together with a comparison with the outputs from the mesoscale MESO-NH model over a period of $24 \mathrm{~h}$ on February 12, 2008. We will then conclude in Section VI.

\section{TheOretiCAL B ACKGROUND}

\section{A. Theory of Operation}

The HAMSTRAD-Tropo radiometer has been developed by the Radiometer Physics GmbH German Company (http:// www.radiometer-physics.de) under the name LHATPRO (Low Humidity And Temperature PROfiler). It uses spectral information in the microwave bands $51-59 \mathrm{GHz}$ (V-band, lower frequency wing of the oxygen line) and 169-197 GHz (G-band, strong water vapor line, centered at $183.3 \mathrm{GHz}$ ) to derive accurate tropospheric profiles of temperature and low humidity (Fig. 1). For temperature profiling, the pressure-broadened oxygen line shape is evaluated, while the strong water vapor line allows for the profiling of very low humidity with an IWV amount of $<2 \mathrm{~kg} \cdot \mathrm{m}^{-2}$ (or $<2 \mathrm{~mm}$ in precipitable water units).

In both cases, a statistical approach is used to calculate the profiles from the brightness temperatures (TBs) measured by the radiometer. The retrieval algorithms are based on a few thousand radio soundings from the area where the instrument 
is deployed (namely, PdM and Dome C), which provide a set of temperature and humidity data points as a function of altitude. Indeed, since 2000, with a periodicity of two launches per day, high-resolution radio soundings from Scott Base at the South Pole (Antarctica) and from Bordeaux-Mérignac (France) have been used to build a statistically relevant database for the Dome C and PdM stations, respectively. From radiative transfer calculations using theoretical spectral models like in [22] or [23], a corresponding set of TBs measured on the surface of the two stations and at the radiometer frequencies is derived. Then, statistical fit algorithms are applied using linear or quadratic regressions to solve the inverse problem, namely, to estimate humidity and temperature profiles from the TB sets. During radiometer operation, the statistical fit coefficients provide an online determination of the tropospheric profiles from the measured TBs. Consequently, the a priori information from the radio soundings is introduced into the retrievals.

While temperature profiling with spectral data from the oxygen line is possible worldwide (oxygen is distributed uniformly over the atmosphere), humidity profiling is more difficult because water vapor distributions from the tropics to the driest places on earth (Antarctica) can vary over more than two orders of magnitude (e.g., IWV up to $70 \mathrm{~kg} \cdot \mathrm{m}^{-2}$ in the tropics and $0.15 \mathrm{~kg} \cdot \mathrm{m}^{-2}$ at Dome C). This wide range of humidity concentrations cannot be measured by evaluating a single water vapor line. For the high humidity levels, a weak water vapor line is favorable (centered at $22.2 \mathrm{GHz}$ ), where the signal is less sensitive to water vapor and thus does not saturate easily. At low humidity levels, a much higher sensitivity for water vapor is required that can be provided by the water vapor line at 183.3 GHz. This line gets easily saturated at places with medium and high humidity levels, like in midlatitudinal, subtropical, and tropical regions. When the line saturates, TBs are basically determined by the environmental temperature in the vicinity of the instrument. Furthermore, no signals from higher altitudes can propagate down to the ground due to excessive absorption. For temperature profiling, the evaluation of the oxygen line is sufficient. For humidity profiling, in particular for low-level humidity, the temperature profile may significantly improve the humidity profile retrieval. Therefore, accurate lowlevel humidity profiling requires the full set of TBs, including oxygen and water vapor lines.

The HAMSTRAD project is focusing on humidity measurements in Antarctica, thus on extremely low humidity concentrations. This makes the radiometric observation of the $183-\mathrm{GHz}$ water vapor line mandatory. Indeed, the weak 22.2-GHz water vapor line is by far too insensitive for Antarctic environmental conditions (IWV $\sim 2 \mathrm{~kg} \cdot \mathrm{m}^{-2}$ ), with an amplitude of only $1 \mathrm{~K}$. At Dome C, where IWV values down to $0.1 \mathrm{~kg} \cdot \mathrm{m}^{-2}$ are observed [24], the water vapor line amplitude at $22.2 \mathrm{GHz}$ would only be $0.1 \mathrm{~K}$.

\section{B. Accuracy of Temperature Profiles}

Temperature profiling has been improved throughout the last ten years (see, e.g., [25]). The frequency and bandwidth of seven channels have been optimally selected to derive the vertical profile of temperature from the oxygen line and are presented in Table I.
TABLE I

Optimized ChANNEL CENTER FREQUENCIES $\left(f_{c}\right)$ AND CORRESPONDING BANDWIDTHS $(B)$ FOR FULL-TROPOSPHERE AND BOUNDARY-LAYER TEMPERATURE PROFILING

\begin{tabular}{lccccccc}
\hline$f_{c}(\mathrm{GHz})$ & 51.26 & 52.28 & 53.86 & 54.94 & 56.66 & 57.30 & 58.00 \\
\hline$B(\mathrm{MHz})$ & 230 & 230 & 230 & 230 & 600 & 1000 & 2000 \\
\hline
\end{tabular}

The vertical profile resolution can be drastically improved in the boundary layer by using a special observation mode (called boundary-layer mode) where the microwave beam is scanned in elevation. The HAMSTRAD-Tropo instrument supports two temperature profiling modes: 1) full-troposphere profiling (frequency scan across the oxygen line in zenith direction) and 2) boundary-layer scanning (elevation scan from 54.9 to $58 \mathrm{GHz}$ ). For boundary-layer temperature profiling, the radiometer beam is scanned in elevation between $5^{\circ}$ and zenith. Note that the observations at $5^{\circ}$ elevation are not contaminated by significant sidelobe contributions (see Section III). At the frequencies from 54.9 to $58 \mathrm{GHz}$, the atmosphere is optically thick. Indeed, the weighting functions peak at 500 and $1000 \mathrm{~m}$ for frequencies of 58 and $54.9 \mathrm{GHz}$, respectively. The receiver stability and accuracy have to be optimized due to the small TB variations that must be resolved in the elevation scanning method. Inside the radiometer, the receiver physical temperature is stabilized to better than $30 \mathrm{mK}$ over the whole operating temperature range (from $-30{ }^{\circ} \mathrm{C}$ to $+40{ }^{\circ} \mathrm{C}$ ) to guarantee a high gain stability during measurements $(>200 \mathrm{~s})$. The receiver noise temperature is minimized to be better than $700 \mathrm{~K}$. In this paper, the temporal resolutions have been fixed to be about 1 and $7 \mathrm{~min}$ for full-troposphere and boundary-layer temperature profiling modes, respectively.

There are several methods to characterize the vertical resolution of measurements. The Backus-Gilbert [26] and the optimal estimation [27] methods are powerful tools that can provide, from an optimal combination of weighting functions, the averaging kernels. Width at half-maximum of the averaging kernels does usually characterize vertical resolution. Unfortunately, neither in neural network nor in regression theories do these kernels simply exist. A bypass indicator is the use of a perturbation theory that consists of perturbing a given profile at a certain height, doing a forward calculation of $\mathrm{TB}$ response, using this TB for a retrieval process, comparing the retrieved versus the original (unperturbed) profile, and seeing how a perturbation is diluted and distributed with height. The perturbation function is usually a delta function peaking at a given altitude with a known width.

Such a perturbation study is going to be presented in forthcoming papers that are actually dealing with the validation of HAMSTRAD-Tropo measurements at PdM [28] and Dome C [29]. In this paper, we only give estimates of the vertical resolutions of temperature and absolute humidity vertical profiles from the HAMSTRAD-Tropo radiometer. These estimates can be considered as first guesses based upon our experience from other radiometers developed at 22 and $60 \mathrm{GHz}$. Since the signal-to-noise ratio at $183 \mathrm{GHz}$ is much intense than at $22 \mathrm{GHz}$ and since the angular resolution of measurements at $183 \mathrm{GHz}$ is much fainter than at $22 \mathrm{GHz}$, the vertical resolution should be better at $183 \mathrm{GHz}$ than at $22 \mathrm{GHz}$. 


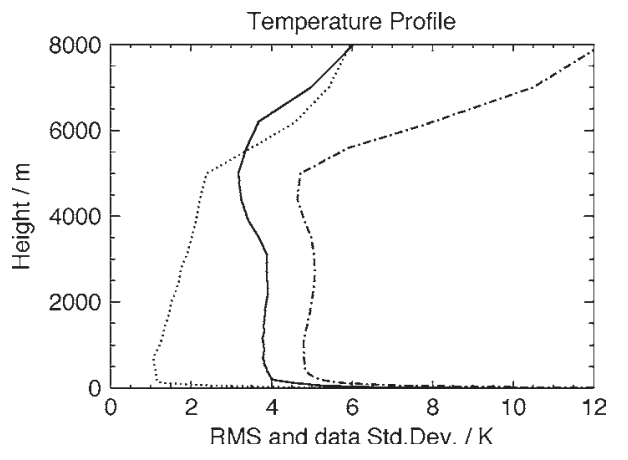

Fig. 2. RMS accuracy of temperature profiling according to the operational modes: (solid line) Full-troposphere and (dotted line) boundary-layer modes, together with the (dashed-dotted line) standard deviation of the radio soundings used in the Dome $\mathrm{C}$ data set.

For both absolute humidity and temperature profile retrievals, the retrieval grid is set to 39 levels, namely, at $0,10,30,50,75$, $100,125,150,200,250,325,400,475,550,625,700,800$, $900,1000,1150,1300,1450,1600,1800,2000,2200,2500$, 2800, 3100, 3500, 3900, 4400, 5000, 5600, 6200, 7000, 8000, 9000 , and $10000 \mathrm{~m}$. The high vertical resolution capability of the boundary-layer mode is critical for the detection of lowlevel temperature inversions that are very common in Antarctica (e.g., $30 \mathrm{~K}$ within $400 \mathrm{~m}$ in the boundary layer). A combination of humidity and temperature sounding channels not only improves the accuracy of absolute humidity profiles but also allows for the determination of relative humidity profiles which show the strong modulation of temperature inversions.

In order to estimate temperature accuracy, we applied the retrieval process to randomly chosen $30 \%$ of the radiosonde data from Dome C (290 soundings from 2006), named as "test" profiles, while the other $70 \%$, named as "true" profiles, were used to make the regression for the retrieval coefficients. For each of the test cases, we obtain an "error," defined as the difference between "true" profiles from the sounding and the profiles retrieved along the retrieval grid from the "test" profiles. The rms error is thus the root mean square of the difference to the mean of a data set considering all the test cases. The solid and dotted lines in Fig. 2 give this rms error for two different retrieval types: full-troposphere retrieval with only zenith pointing and the boundary-layer mode with angular scanning mode, respectively. The standard deviation is calculated from the variability of the "true" profiles and is represented by the dashed-dotted line in Fig. 2. In the case of the Dome C atmosphere, the variability of the tropospheric temperature is ranging between 5 and $8 \mathrm{~K}$, namely, greater than the rms error for boundary-layer (1-2 K) and full-troposphere (3-4 K) modes of observation.

The accuracy of the retrieval outputs at Dome $\mathrm{C}$ can be derived according to the observational modes (Fig. 2).

1) Full-troposphere temperature profiles (0-8000 m): Profile accuracy is about 3-4 K rms below $5000 \mathrm{~m}$ and greater than 4-K rms above; we estimate the vertical resolution to be $200 \mathrm{~m}$ below $5000-\mathrm{m}$ altitude and $400 \mathrm{~m}$ above.

2) Boundary-layer temperature profiles $(0-2000 \mathrm{~m})$ : Profile accuracy is about $1-\mathrm{K}$ rms below $1000 \mathrm{~m}$ and about $2-\mathrm{K}$ rms above with a vertical resolution estimated to be about $50 \mathrm{~m}$.

\section{Accuracy of Humidity Profiles}

The same profiling observation modes can be applied to humidity profiling with the $183-\mathrm{GHz}$ line. The oxygen line channels are also included in the humidity retrieval using the six optimized channels listed in Table II.

Regarding the retrieval, we do not use any surface sensor readings for input, only the 13 frequencies. All 13 frequencies are used for IWV as well as absolute humidity profile retrievals, but at different angle schemes. No quadratic terms of the TB values are used for the retrievals, only linear.

The IWV retrieval uses 26 inputs, namely, 13 frequencies at $90^{\circ}$ elevation (zenith observations) and also at $30^{\circ}$ elevation. We use this for the real Dome $\mathrm{C}$ retrievals due to the opposite effect of saturation with high IWV. At Dome C, the signal from the outer channels $( \pm 4.5, \pm 7 \mathrm{GHz})$ is too low to be meaningful; even close to the line center, the signal is not saturated. By using TBs at low elevation, we increase the signal in the outer channels while saturating (and thus reducing the penetration depth into the atmosphere) for the center channels.

The absolute humidity profile retrievals use 66 inputs, namely, 13 channels at $90^{\circ}$ and $42^{\circ}$ elevations, and 10 channels at $30.0^{\circ}, 19.2^{\circ}, 10.2^{\circ}$, and $5.4^{\circ}$ elevations (leaving out the first three channels of the oxygen line). Unfortunately, using quadratic terms would double the number of input channels and make the regression unstable.

First preliminary results of radiative transfer calculations indicate the following accuracies for the Dome C site (Fig. 3).

1) Full-troposphere humidity profiles $(0-8000 \mathrm{~m})$ : Profile accuracy of $0.03 \mathrm{~g} \cdot \mathrm{m}^{-3} \mathrm{rms}(0-2000 \mathrm{~m})$, and $0.01 \mathrm{~g} \cdot \mathrm{m}^{-3} \mathrm{rms}(>2000 \mathrm{~m})$; we estimate the vertical resolution to be $500 \mathrm{~m}$ below 4000-m altitude and $1000 \mathrm{~m}$ above.

2) Boundary-layer humidity profiles $(0-2000 \mathrm{~m})$ : Profile accuracy of $0.03 \mathrm{~g} \cdot \mathrm{m}^{-3} \mathrm{rms}$ with a vertical resolution estimated to be $100 \mathrm{~m}$.

If we now consider some bias between observed TB and gas absorption model used in radiative transfer calculations, the accuracy of the measured absolute humidity will degrade to $0.05 \mathrm{~g} \cdot \mathrm{m}^{-3}$ in the domain $0-3 \mathrm{~km}$ above the radiometer and $0.02 \mathrm{~g} \cdot \mathrm{m}^{-3}$ above $3000 \mathrm{~m}$.

At the $\mathrm{PdM}$ station, the amount of $\mathrm{H}_{2} \mathrm{O}$ is about ten times the amount of $\mathrm{H}_{2} \mathrm{O}$ encountered above the Dome $\mathrm{C}$ station, and the higher $\mathrm{H}_{2} \mathrm{O}$ density makes opaque some of the instrument channels. Furthermore, the absolute humidity accuracy is ranging from about $0.6 \mathrm{~g} \cdot \mathrm{m}^{-3} \mathrm{rms}$ at the surface to about $0.2 \mathrm{~g} \cdot \mathrm{m}^{-3}$ rms at $4000 \mathrm{~m}$ above the radiometer (Fig. 3).

Based on the radiosonde data from Dome C (290 soundings from 2006), we calculated the microwave TBs for downwelling radiation at several elevation angles. By adding instrument noise $(0.5-\mathrm{K} \mathrm{rms})$, we obtained a synthetic radiometer measurement. A multivariate quadratic (sometimes only linear) regression established the inversion of forward-calculated TBs to atmospheric parameters. Only $80 \%$ of the data (randomly chosen) were used for the regression, and the remaining $20 \%$ were used for algorithm testing. As an example, the algorithm performance results are shown in Fig. 4 for three retrievals selected because they are corresponding to low, medium, and high humidities over Dome C. Although the results are preliminary and will need to be validated with actual measurements 
TABLE II

Optimized Channel Center Frequencies $\left(f_{c}\right)$, IF Channel Center Frequencies $\left(F_{\text {IF }}\right)$, AND CORRESPONDING BANDWIDTHS FOR HUMIDITY PROFILING

\begin{tabular}{lcccccc}
\hline$f_{c}(\mathrm{GHz})$ & $183.31 \pm 0.6$ & $183.31 \pm 1.5$ & $183.31 \pm 2.5$ & $183.31 \pm 3.5$ & $183.31 \pm 4.5$ & $183.31 \pm 7.0$ \\
\hline$F_{I F}(\mathrm{GHz})$ & 0.6 & 1.5 & 2.5 & 3.5 & 4.5 & 7.0 \\
\hline$B(\mathrm{MHz})$ & 200 & 200 & 200 & 200 & 500 & 1000 \\
\hline
\end{tabular}
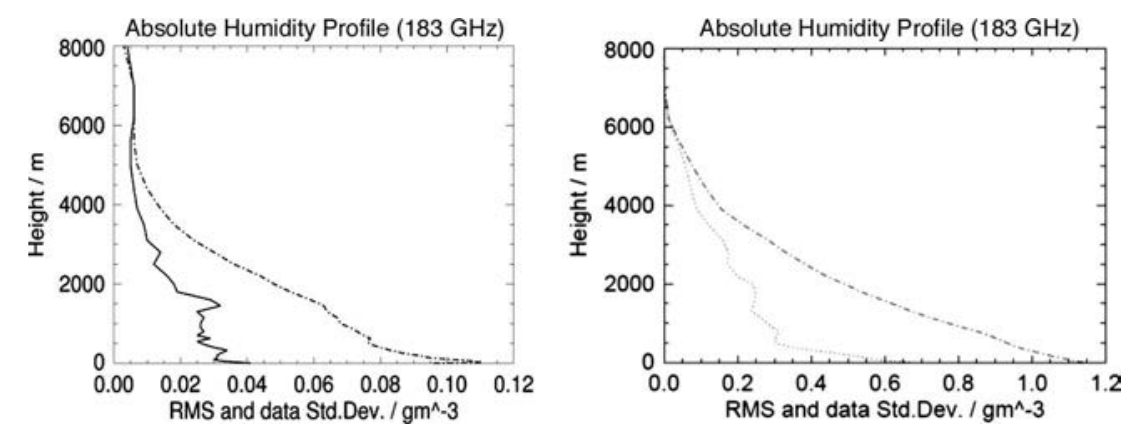

Fig. 3. (Solid or dotted lines) Absolute humidity retrieval rms accuracy and (dashed-dotted line) standard deviation of the radio soundings used in the (left) Dome C and (right) PdM data sets.
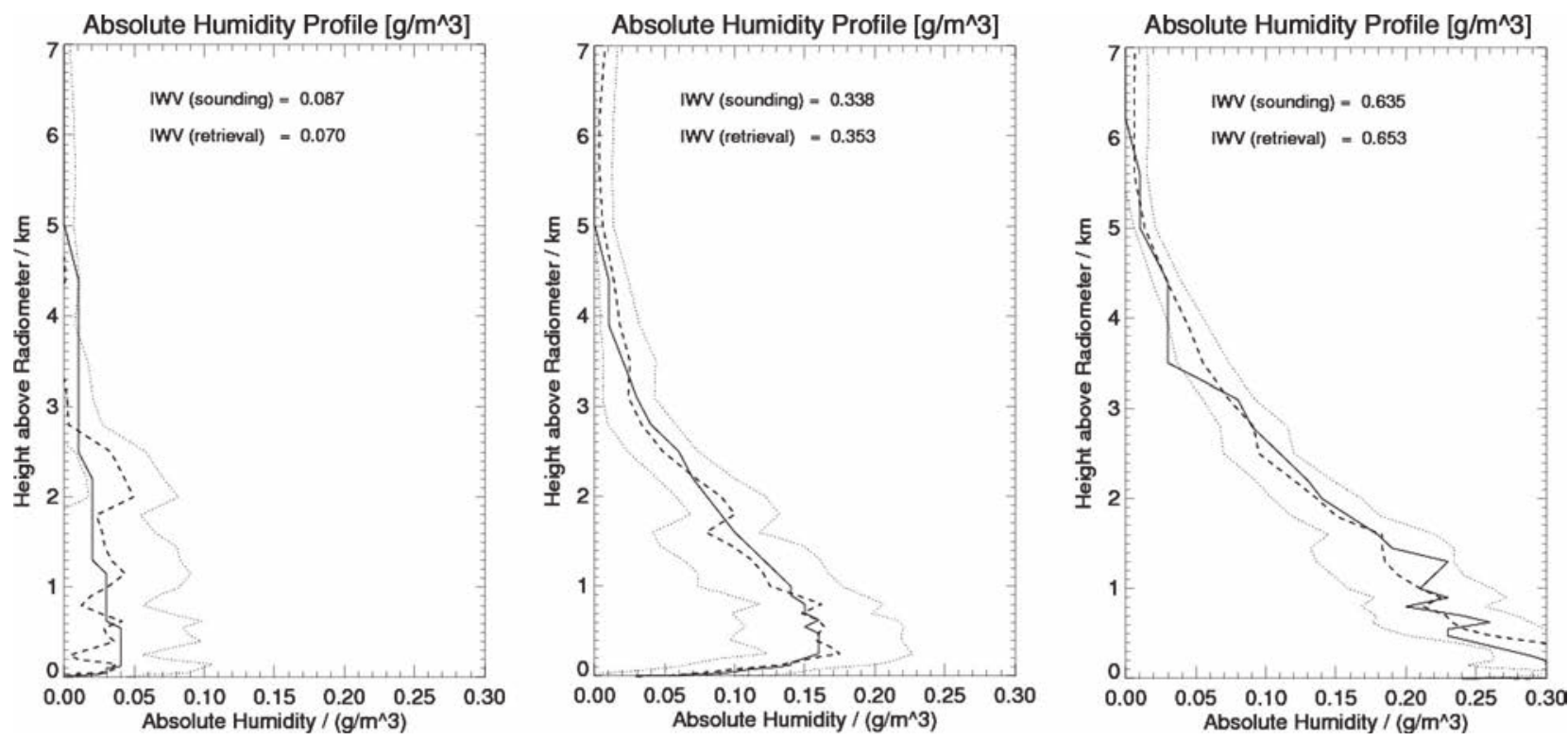

Fig. 4. Absolute humidity profiles for three single examples corresponding to (left) dry, (center) medium, and (right) wet atmospheres at Dome C. The (solid line) "true" profile is coming from a radio sounding; the (dashed line) profile retrieved from the retrieval process together with its (dotted lines) associated rms error. IWVs (in kilograms per square meter) estimated from the vertical sounding and retrieved profiles are also shown.

at Dome $\mathrm{C}$, absolute humidity profiling estimated with the regression methods applied to the unused $20 \%$ of the data matches the radio soundings to within $0.02 \mathrm{~g} \cdot \mathrm{m}^{-3}$ whatever the type of the troposphere considered. A retrieval analysis based on all 13 channels ( 7 channels covering the $\mathrm{O}_{2}$ band and 6 channels covering the $\mathrm{H}_{2} \mathrm{O}$ band) shows an rms noise of $0.008 \mathrm{~g} \cdot \mathrm{m}^{-3}$. Also note that the IWVs estimated from the sounding and retrieved profiles agree to within $0.02 \mathrm{~kg} \cdot \mathrm{m}^{-2}$.

The natural variability (namely, the standard deviation) of IWV is $0.189 \mathrm{~kg} \cdot \mathrm{m}^{-2}$ at Dome C. A comparison of retrieval output with the $20 \%$ test data yields an rms noise of $0.008 \mathrm{~kg} \cdot \mathrm{m}^{-2}$ (Fig. 5). The rms noise of IWV retrievals shows a linear dependence on the absolute humidity level and is typically about $5 \%$. In principle, IWV can be calculated as an integral over the absolute humidity profiles. For the HAMSTRAD-Tropo radiometer, we developed a separate IWV retrieval scheme, independent from the profile retrieval, which is intended to be a consistency check for both retrieval types.

The LWP accuracy is about $10-20 \mathrm{~g} \cdot \mathrm{m}^{-2}$ with an $\mathrm{rms}$ noise of $5 \mathrm{~g} \cdot \mathrm{m}^{-2}$. LWP can be estimated from the transparent oxygen channels and from the $183.31 \pm 7-\mathrm{GHz}$ channel which is a window channel under the dry Antarctic conditions (see also [16]).

\section{HAMSTRAD-TROPO RADIOMETER}

The HAMSTRAD-Tropo radiometer is a compact fully automated instrument. Its dimensions are $36 \times 65 \times 115 \mathrm{~cm}^{3}$. 


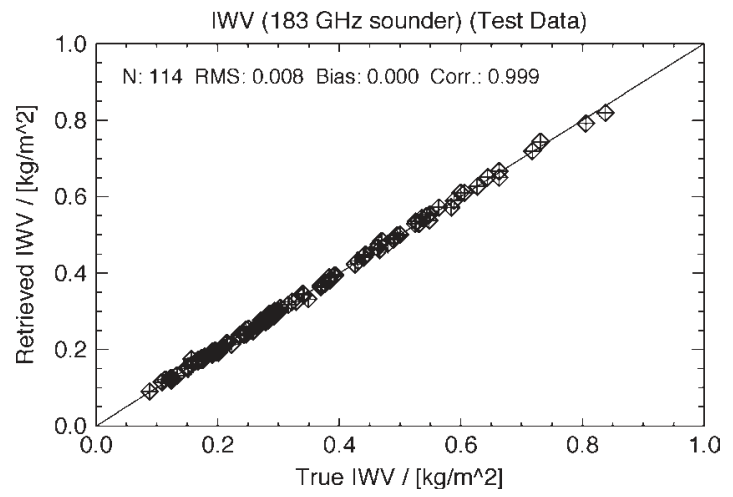

Fig. 5. Scatter plot of true versus estimated IWVs based upon the $183-\mathrm{GHz}$ retrieval scheme applied to the Dome $\mathrm{C}$ data set.

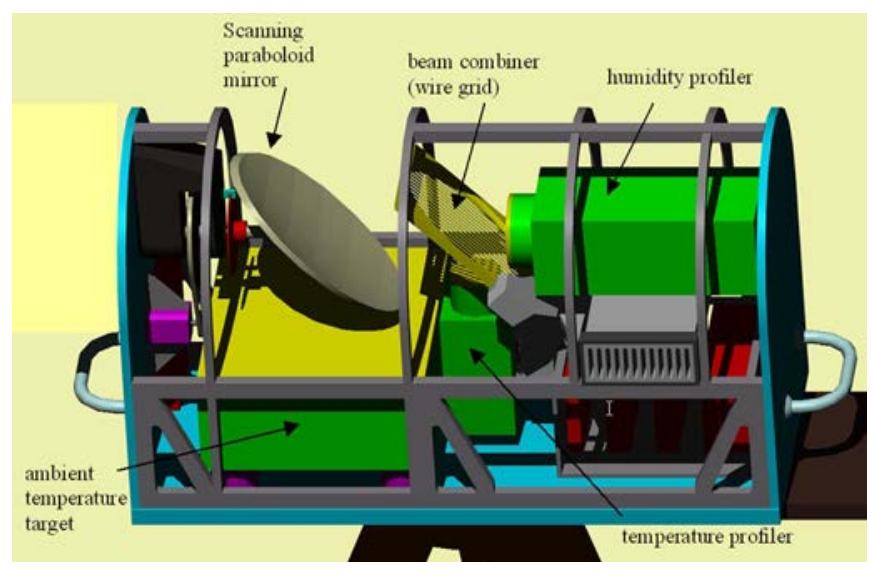

Fig. 6. Internal structure of the HAMSTRAD-Tropo radiometer.

Fig. 6 shows the schematic radiometer setup. The two profiler receiver modules are oriented orthogonally, and the two beams are superimposed by a wire grid beam combiner. An off-axis parabola mirror forms an image on the sky with $\sim 2^{\circ}$ halfpower beam width. The parabola mirror scans the ambient temperature calibration target underneath the mirror and is also used for boundary-layer scanning modes. The receiver modules and their feed horns are encapsulated in thermal insulation, and a two-stage stabilization system (regulated cooler and Peltier stages) stabilizes the receivers to better than $30 \mathrm{mK}$ over the full operating temperature range. This high stability is essential to fulfill the radiometric stability requirements in the boundarylayer mode (namely, 0.1-K rms).

\section{A. Receivers}

1) Temperature Receiver: The temperature profiler receiver is realized as a direct detection filter bank design. Fig. 7 shows a schematic of the receiver system. At the receiver inputs, a directional coupler allows for the injection of a precision noise signal generated by an on/off switching calibrated noise source. This noise signal is used to determine system nonlinearities (four-point method) and system noise temperature drifts during measurements. A 60-dB low-noise amplifier (LNA) boosts the input signal before it is split into eight branches (only seven are currently used). The splitter implements waveguide band-pass filters. Each channel has its own detector diode. This allows for a parallel detection and integration of all channels which implies a fast scanning of the oxygen line. The detector outputs are amplified by an ultralow drift operational amplifier chain and multiplexed to a 16-bit analog-to-digital converter (ADC).

The receivers are based on the direct detection technique without using mixers and local oscillators for signal downconversion. Instead, the input signal is directly amplified, filtered, and detected. The advantages over a heterodyne system are the following. 1) No mixers and local oscillators are required (cost reduction). 2) Local oscillator drifts in amplitude and frequency are avoided (stability improvement). No synthesizer is needed. The radiometer is purely passive without oscillator power leakage that might interfere with other instruments. 3) Mixer sideband filtering is not required (cost reduction). 4) Sensitivity to interfering external signals (mobile phones, etc.) is reduced due to avoidance of frequency downconversion.

The filter bank concept (parallel channel layout) has the following advantages over sequentially scanning radiometers (e.g., synthesizer sweeping receivers and spectrum analyzers): 1) simultaneous measurements of all frequency channels; 2) much higher temporal resolution for all products (1 s); 3) faster calibration procedures; and 4) individual channel bandwidth selection (critical for boundary-layer temperature profiling). A high integration level is achieved due to the use of state-of-the-art LNA monolithic microwave integrated circuits, which offer superior sensitivity performance compared to mixers. The total power consumption of the receiver package is $<3 \mathrm{~W}$. This includes biasing of radio-frequency (signal) and direct-current amplifiers, noise diodes, ADCs, and digital control circuits. The low consumption simplifies the thermal receiver stabilization with an accuracy of $<0.03 \mathrm{~K}$ over the whole operating temperature range $\left(-30{ }^{\circ} \mathrm{C}\right.$ to $\left.+40{ }^{\circ} \mathrm{C}\right)$.

2) Humidity Receiver: The humidity profiling receiver design is a double-sideband heterodyne system (Fig. 8) with a set of frequencies optimized for the intermediate frequency (IF) listed in Table II.

The water vapor line is symmetrical so that both line wings can be detected in parallel by the double-sideband detection. This doubles the receiver sensitivity. A low-noise subharmonic mixer is used as the front-end component with a wide IF bandwidth of $0.4-20 \mathrm{GHz}$. The mixer noise temperature is close to $500 \mathrm{~K}$. Receiver gain fluctuations are calibrated by a precision noise standard that is periodically $(100 \mathrm{~Hz})$ injected into the receiver input. The overall system noise temperature, including noise injection section and IF-chain noise temperature, is approximately $1500 \mathrm{~K}$. The local oscillator comprises a dielectric resonant oscillator (DRO) operating at $30.55 \mathrm{GHz}$ followed by a frequency tripler. The DRO itself derives its output frequency from a doubled $15.27-\mathrm{GHz}$ oscillator. Thus, there will be no interference in the $22-\mathrm{GHz}$ water vapor band used, for instance, by other instruments for stratospheric water vapor measurements.

\section{B. Calibrations}

The HAMSTRAD-Tropo radiometer uses an automatic selfcalibrating system. A well-known amount of noise (determined during absolute calibration with liquid nitrogen) is periodically $(100 \mathrm{~Hz})$ injected into the receiver inputs, which calibrates gain drifts. In addition, system noise temperature drifts are 


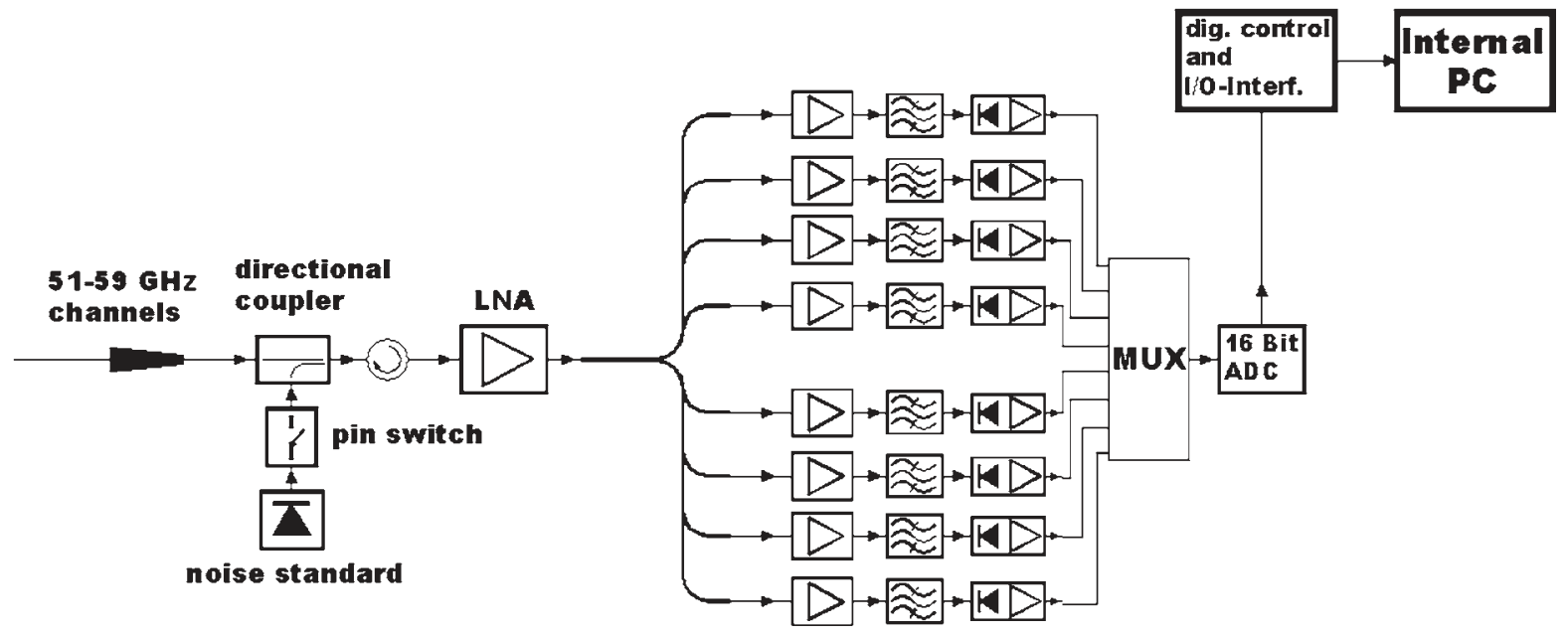

Fig. 7. Temperature profiling receiver design of the HAMSTRAD-Tropo radiometer.

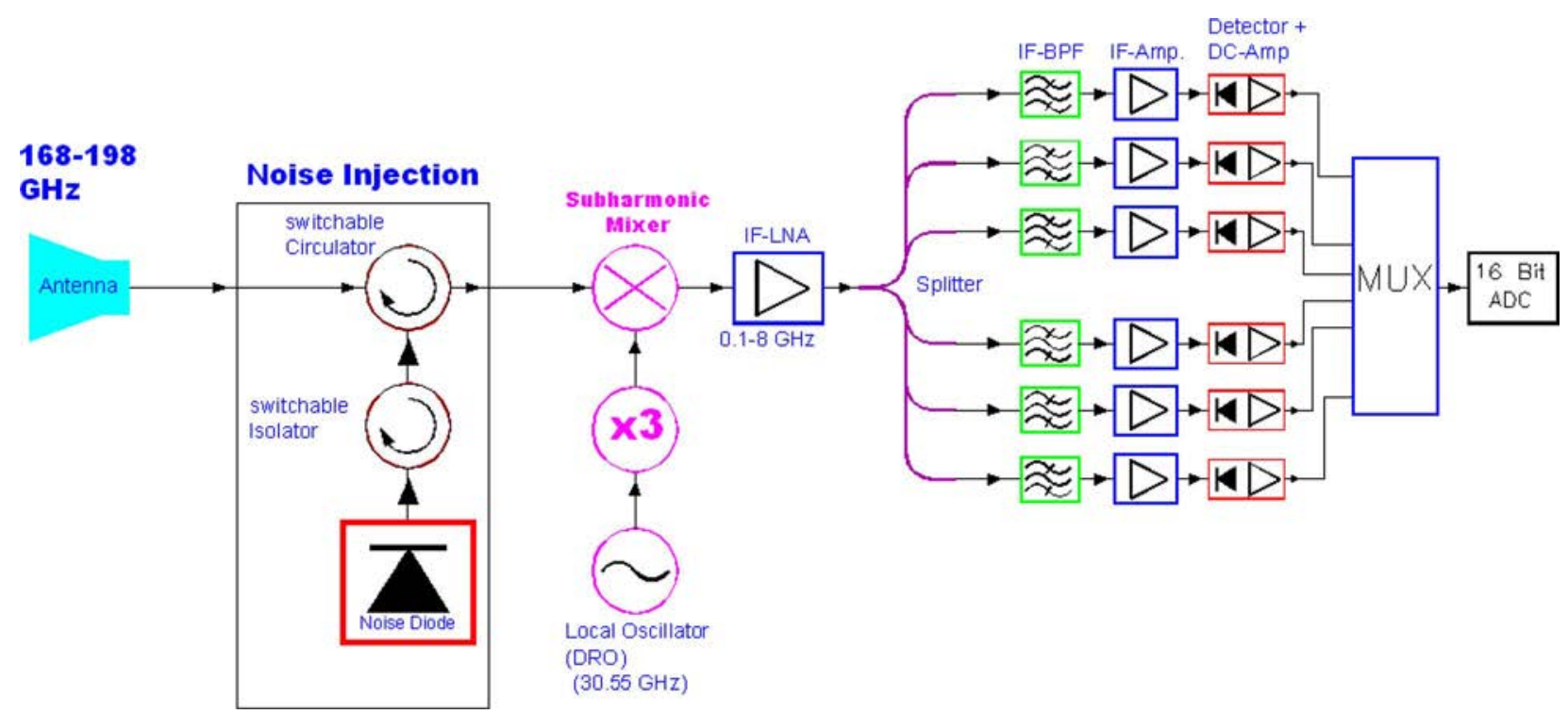

Fig. 8. Humidity profiling heterodyne receiver layout.

compensated by switching the elevation mirror to the built-in ambient temperature target. The noise standards are secondary calibration standards that have to be calibrated by an absolute calibration using an external liquid-nitrogen-cooled target. This manual calibration should be repeated every six months. All calibration parameters are continuously stored in a calibration $\log$ file.

\section{Additional Sensors}

Apart from the microwave receivers, the HAMSTRADTropo radiometer is equipped with the following additional sensors: 1) an environmental temperature sensor (accuracy of $0.5{ }^{\circ} \mathrm{C}$ ); 2 ) a humidity sensor (accuracy of $5 \%$ relative humidity); 3) a barometric pressure sensor (accuracy of $0.5 \mathrm{mbar}$ ) used for the determination of liquid-nitrogen boiling temperature (for absolute calibration); 4) a rain sensor (the rain flag of this sensor is used for all measurements as additional information and for operating the dew blower fan speed); and 5) a GPS receiver that receives instrument position and UTC time that is used as time standard for exact time synchronization.

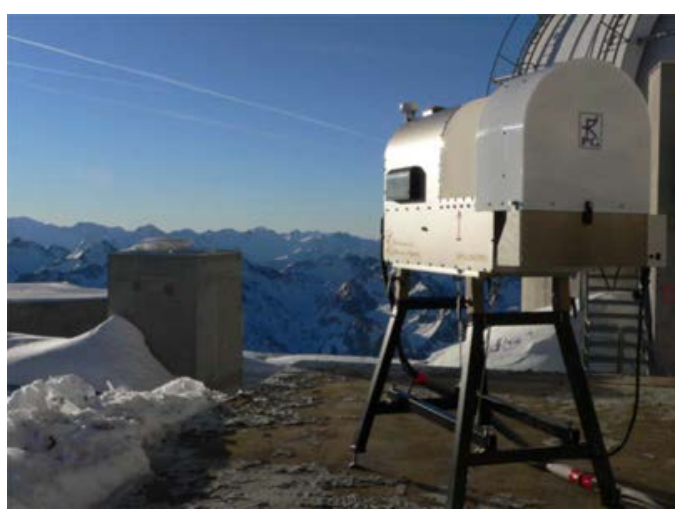

Fig. 9. HAMSTRAD-Tropo radiometer on the terrace of PdM in February 2008.

\section{First Measurements at PdM}

The HAMSTRAD-Tropo radiometer (Fig. 9) has been installed at PdM on February 6, 2008. The PdM facility covers 


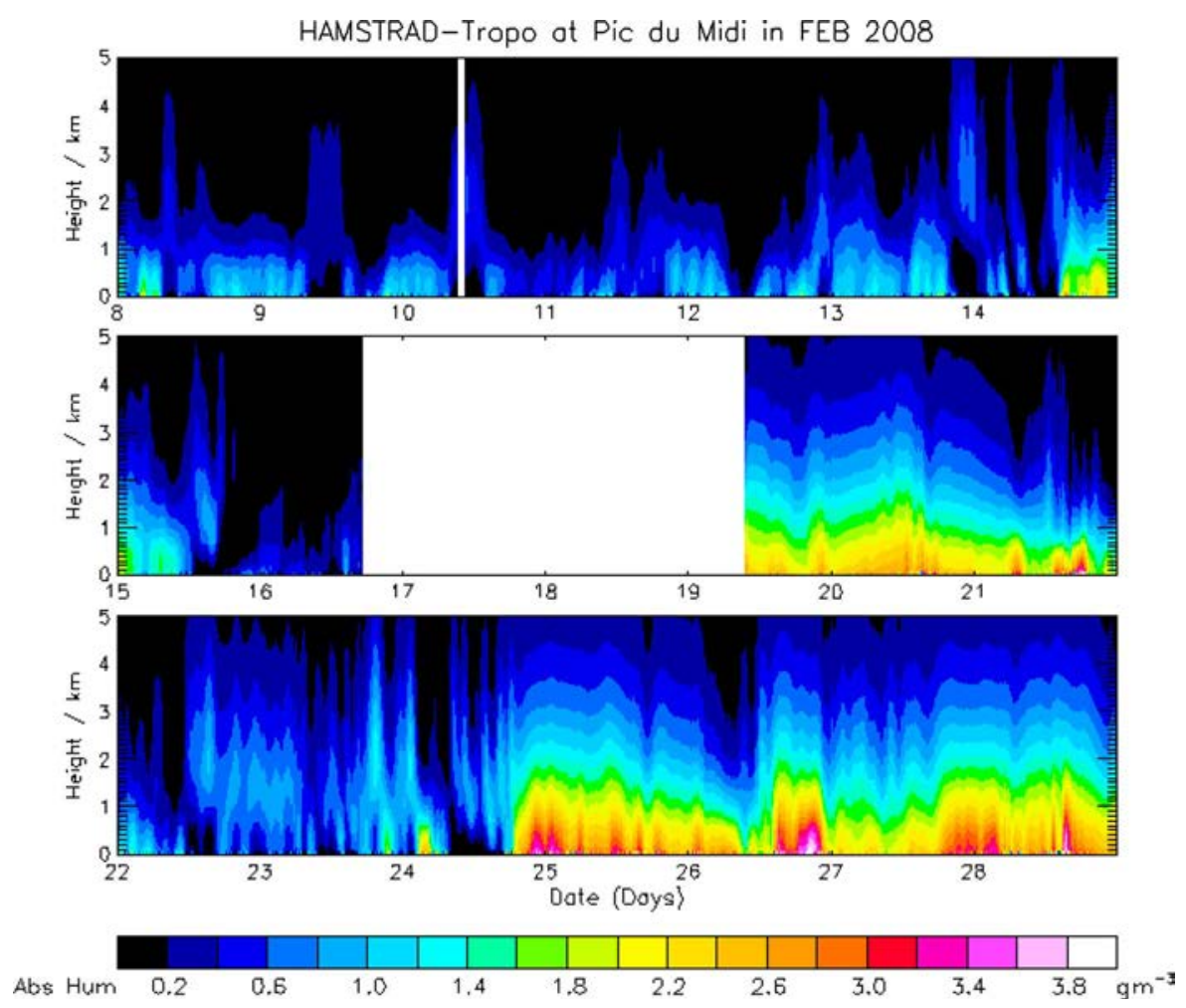

Fig. 10. Temporal evolution of the absolute humidity as measured by HAMSTRAD-Tropo above the altitude of PdM (altitude $=0)$ in February 2008. Note the gap covering the $48 \mathrm{~h}$ on February $17-18$ due to a power failure at the PdM facility.

a wide range of scientific applications from astronomical to atmospheric issues. It has recently been hosting the Pollution Atmosphérique à Echelle Synoptique program dedicated to the in situ measurements of pollutants [30]. After a liquid-nitrogen calibration procedure, HAMSTRAD-Tropo has been started working over the period February-June 2008 with no major instrumental failure except some external power failure induced by the local infrastructure, since the instrument was not initially plugged onto an uninterruptible power supply.

We mainly focus the present analysis onto the month of February 2008 for three main reasons. First of all, the meteorological conditions encountered during the beginning of February 2008 were rather unusual with a strong anticyclone blocked over western Europe producing a cloud-free and very dry atmosphere over several days. We, indeed, will show in the next section that, in terms of absolute humidity, weather conditions over PdM on that particular winter period were very close to the ones encountered during summer seasons at Dome C. Second, we run a systematic program of 20 radiosonde launches from the site of Lannemezan $\left(43^{\circ} 07^{\prime} \mathrm{N}, 0^{\circ} 23^{\prime} \mathrm{E}, 610 \mathrm{~m}\right.$ asml, France), about $50 \mathrm{~km}$ northeast from PdM, again during the February-March 2008 period around 12:00 UTC. This program was in complement to the routinely meteorological soundings performed at 00:00 and 12:00 UTC in Bordeaux-Mérignac Airport $\left(44^{\circ} 49^{\prime} \mathrm{N}, 0^{\circ} 42^{\prime} \mathrm{W}, 50 \mathrm{~m}\right.$ asml, France) and in Zaragoza $\left(41^{\circ} 39^{\prime} \mathrm{N}, 0^{\circ} 53^{\prime} \mathrm{W}, 263 \mathrm{~m}\right.$ asml, Spain) we have also used in our validation approach. Third, the validation of HAMSTRADTropo over the entire February-June 2008 period during different weather conditions against radiosondes and satellite measurements, and the interpretation of the measurements by comparisons with the mesoscale MESO-NH model will be dealt within another forthcoming manuscript [28].
Fig. 10 shows the very first set of water vapor measurements from HAMSTRAD-Tropo covering the month of February 2008, from the 8th to the 28th. Note the gap covering the $48 \mathrm{~h}$ on February $17-18$ due to a power failure at the PdM facility. Figs. 11 and 12 also show, over the same period, the temporal evolution of temperature vertical profiles and of the temperature anomaly (difference between temperature and averaged temperature fields), respectively, as measured by HAMSTRAD-Tropo. Finally, Figs. 13 and 14 show, again over the same period, the IWV and LWP measured by HAMSTRAD-Tropo above PdM, respectively.

The temporal evolution of the vertical $\mathrm{H}_{2} \mathrm{O}$ profiles as measured by HAMSTRAD-Tropo shows a large variability for extreme weather conditions: dry (prior to February 17) with values less than $1.0 \mathrm{~g} \cdot \mathrm{m}^{-3}$ when temperature field is decreasing and wet (after February 19) with values greater than $3.0 \mathrm{~g} \cdot \mathrm{m}^{-3}$ when temperature field is increasing. Considering now the dry period, an obvious diurnal variability is detected in the measured data sets with minima around noon and maxima around midnight, with an interesting local maximum peaking $\sim 2 \mathrm{~km}$ above the altitude of the PdM site with no obvious correlation with the temperature or temperature anomaly fields. When considering the wet period, the vertical distribution of $\mathrm{H}_{2} \mathrm{O}$ is somewhat very consistent to what we expect from climatology, namely, a decrease with height above the site.

Prior to February 17, the atmosphere above PdM is exceptionally dry, with long periods with IWV less than $2 \mathrm{~kg} \cdot \mathrm{m}^{-2}$ (February 7-13, February 16, and few hours on 22 and on February 24) and several few-hour long periods of extremely dry conditions with IWV less than $1 \mathrm{~kg} \cdot \mathrm{m}^{-2}$ (February 9, $10,12,14$, and 16). IWVs as calculated from $\mathrm{H}_{2} \mathrm{O}$ profiles measured by sondes in Bordeaux, Lannemezan, and Zaragoza 


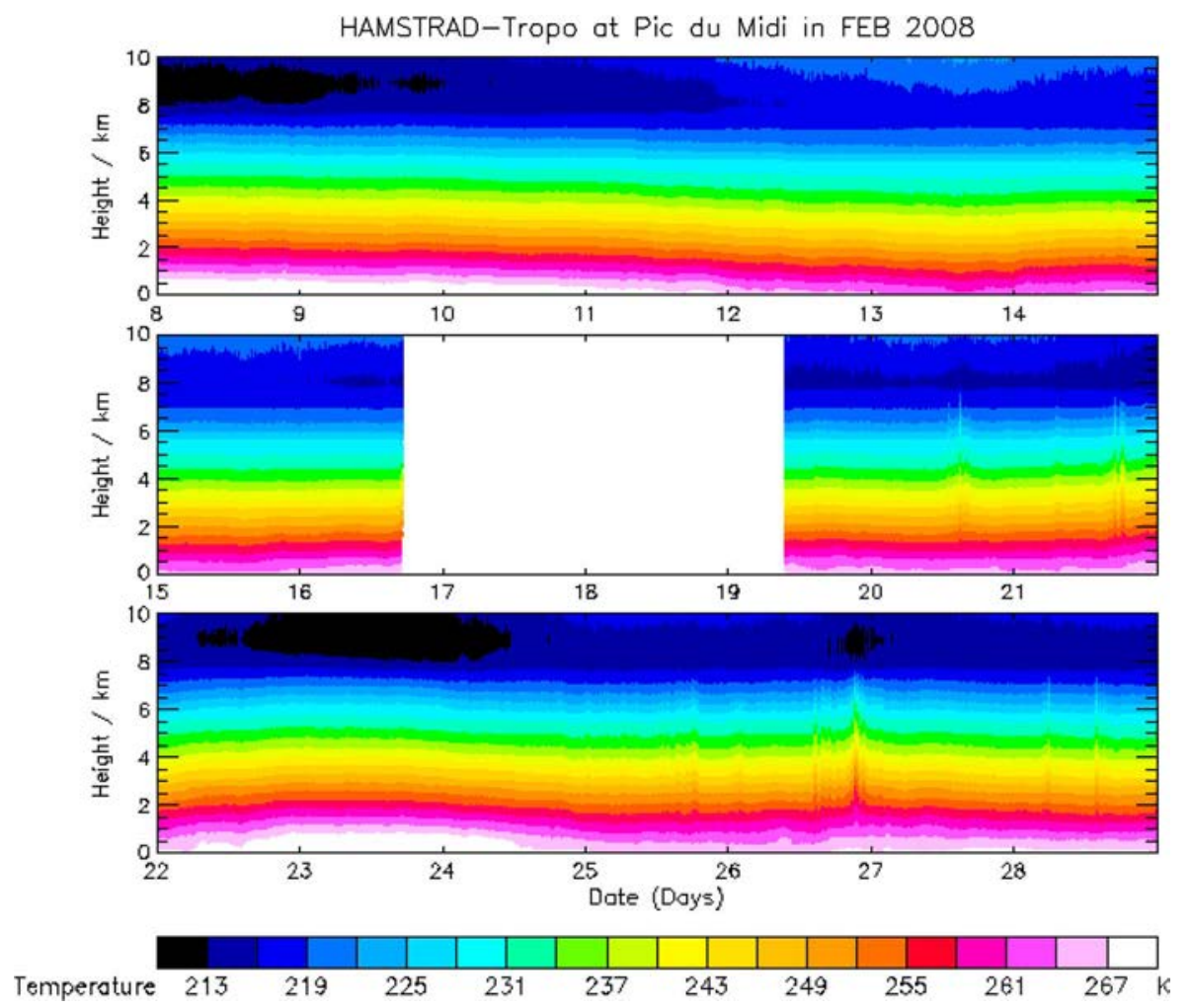

Fig. 11. Temporal evolution of the temperature as measured by HAMSTRAD-Tropo above the altitude of PdM (altitude $=0)$ in February 2008. Note the gap covering the $48 \mathrm{~h}$ on February $17-18$ due to a power failure at the PdM facility.
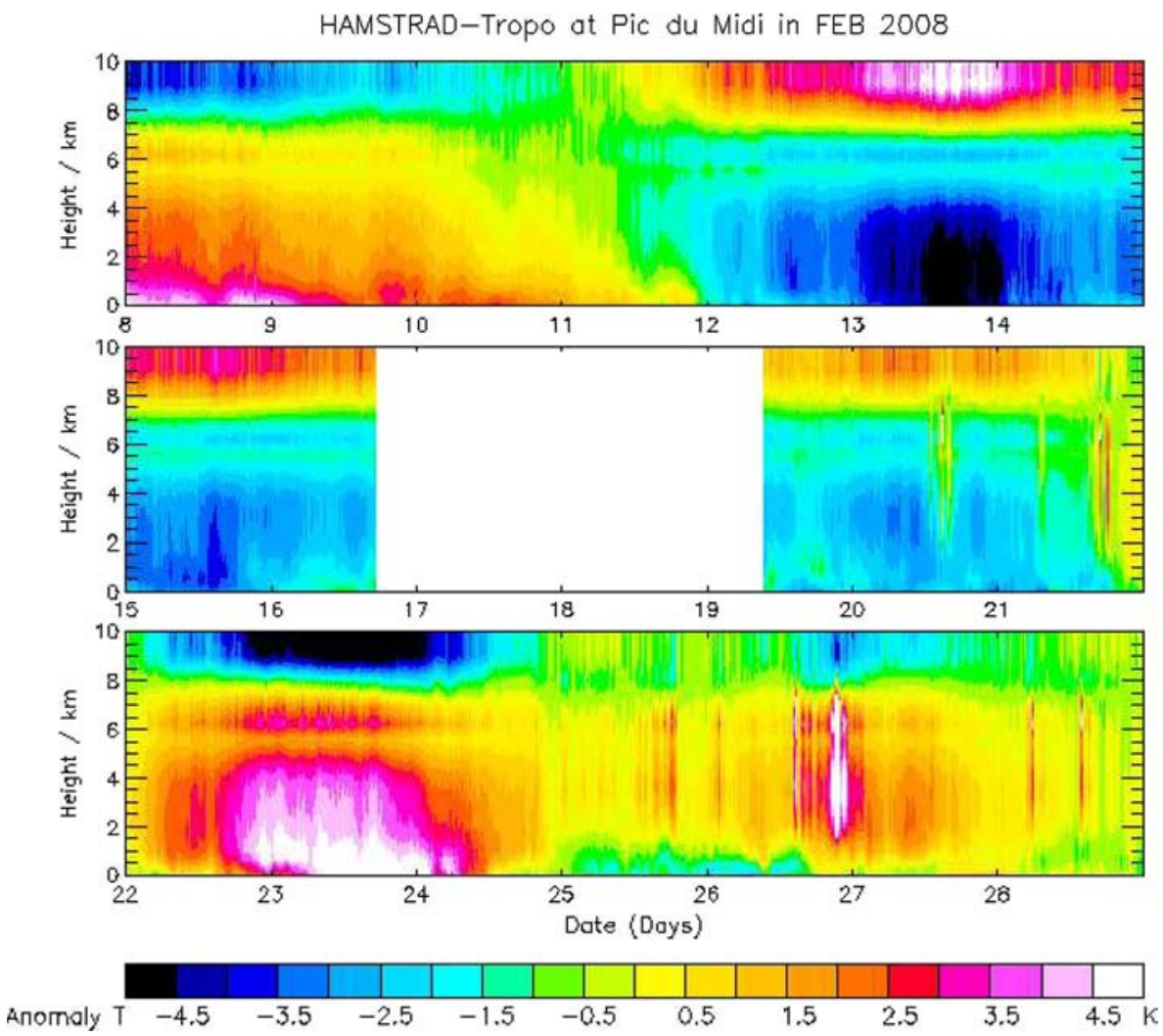

Fig. 12. Temporal evolution of the temperature anomaly (difference between temperature and averaged temperature fields) as measured by HAMSTRAD-Tropo above the altitude of PdM (altitude $=0$ ) in February 2008. Note the gap covering the $48 \mathrm{~h}$ on February 17-18 due to a power failure at the PdM facility.

(and presented in the next section) do also show such a dry condition in very good agreement with HAMSTRAD-Tropo. Indeed, a strong anticyclone was blocked over western Europe in the beginning of February with depressions starting being very active later. It is indeed well detected by the HAMSTRADTropo instrument that measured negligible amounts of LWP 

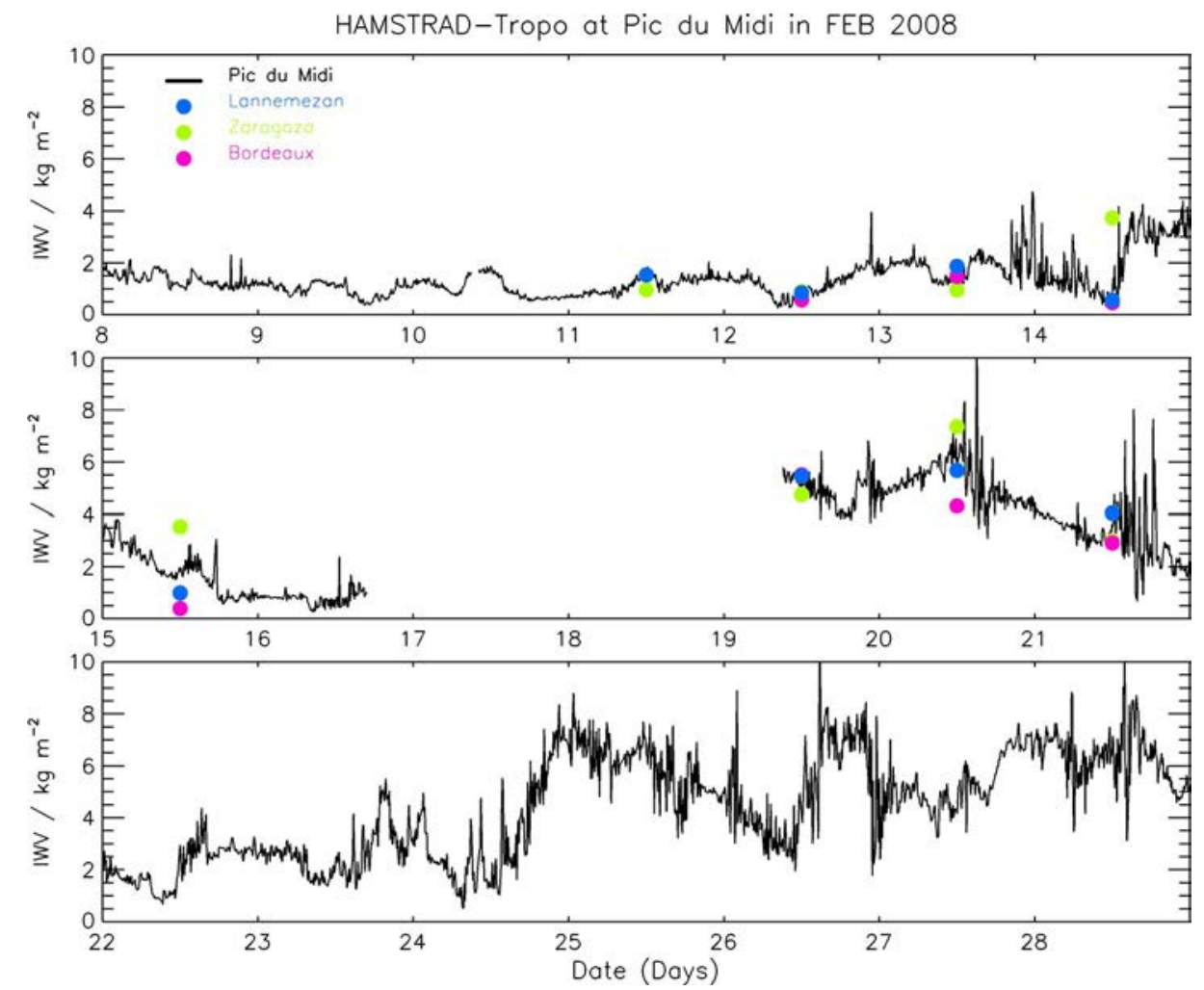

Fig. 13. Temporal evolution of the IWV as measured by HAMSTRAD-Tropo above the altitude of PdM in February 2008. Note the gap covering the 48 h on February 17-18 due to a power failure at the PdM facility. Also shown are the IWVs estimated from the vertical profiles of $\mathrm{H}_{2} \mathrm{O}$ as measured by the sondes in (blue-filled circle) Lannemezan, (green-filled circle) Zaragoza, and (red-filled circle) Bordeaux above $2877 \mathrm{~m}$.
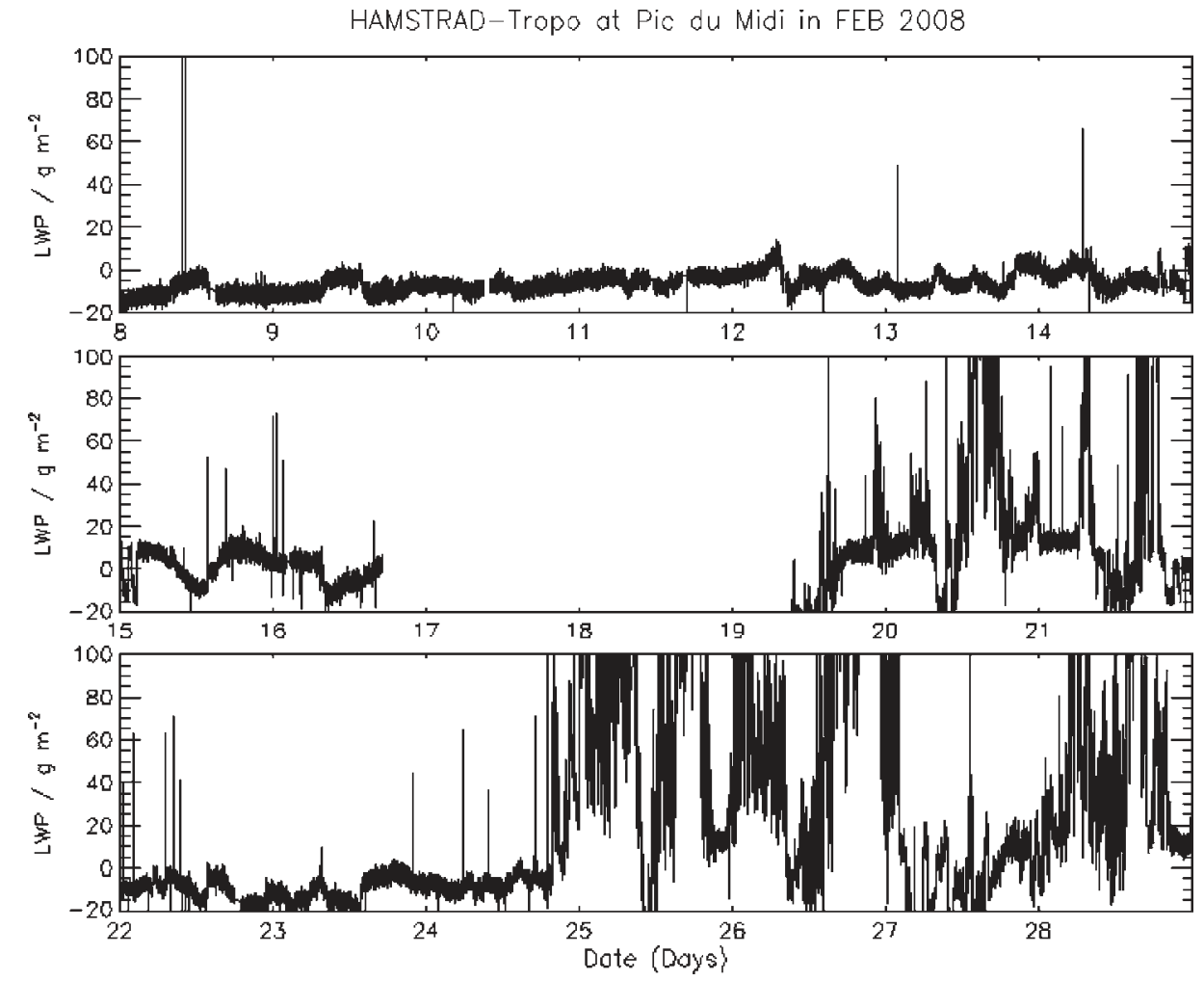

Fig. 14. Temporal evolution of the LWP as measured by HAMSTRAD-Tropo above the altitude of PdM in February 2008. Note the gap covering the 48 h on February $17-18$ due to a power failure at the PdM facility.

(actually even negative values of about $-10 \mathrm{~g} \cdot \mathrm{m}^{-2}$ ) before February 15. After February 19, the great variability in the measured LWP (from 20 to more than $100 \mathrm{~g} \cdot \mathrm{m}^{-2}$ ) mimics the presence of clouds in the field of view of the instrument. At this stage, it is beyond the scope of this paper to assess both the presence and the nature of the clouds as estimated 
from the measurements of the LWP parameter and the quality of the retrieved LWP parameter mainly because coincident measurements are missing. Furthermore, since, at Dome C, it is highly probable that LWP tends to be negligible, we do not expect to measure this parameter over there and have not implemented any retrieval procedure for this site. The fact that during clear-sky conditions the retrievals produce a negative bias in LWP may be a symptom of a bias in the calibration or in the radiative transfer model. The main point is to underline the extreme sensitivity of HAMSTRAD-Tropo to the presence of clouds through the measurement of LWP from the $50-60-\mathrm{GHz}$ and the $183-\mathrm{GHz}$ receivers, while the measured vertical distribution of $\mathrm{H}_{2} \mathrm{O}$ from the $183-\mathrm{GHz}$ receiver does not appear to be altered (see next section). Note also that the extremely high amounts of IWVs as detected by HAMSTRAD-Tropo $\left(4-6 \mathrm{~kg} \cdot \mathrm{m}^{-2}\right)$ on February 19-21 agree very well with IWVs calculated from sonde $\mathrm{H}_{2} \mathrm{O}$ profiles measured in Bordeaux, Lannemezan, and Zaragoza and show consistent variability.

\section{Preliminary VAlidation}

\section{A. Sondes}

The Modem M2K2 and M2K2DC radiosondes (width: $92 \mathrm{~mm}$; length: $107 \mathrm{~mm}$; height: $160 \mathrm{~mm}$; weight: $210 \mathrm{~g}-$ including batteries) were used during the experiment. They were configured for temperature and humidity measurements. Communication with the station is established by radio (400-406 MHz). The temperature sensor is a thermistor (range: $-90{ }^{\circ} \mathrm{C}$ to $+55{ }^{\circ} \mathrm{C}$; resolution: $0.1{ }^{\circ} \mathrm{C}$; accuracy: $\pm 0.5{ }^{\circ} \mathrm{C}$; response: $<2 \mathrm{~s}$ ). It received a treatment to avoid problem from humidity and solar radiation. The humidity sensor is a capacitor, which capacitance is a function of relative humidity (range: $0 \%-100 \%$; resolution: $0.1 \%$; accuracy: $\pm 5 \%$; response: $<2 \mathrm{~s}$ ). It is protected by a cap against both rain and mechanical risks. Pressure is calculated, according to Laplace law, from temperature, humidity, and GPS altitude. GPS also allows determination of wind direction and intensity. Temperature and humidity sensors are first calibrated by the manufacturer and then by a user before launch. Measurement frequency is $1 \mathrm{~Hz}$. Radiosonde launches were mainly performed in February-March 2008 (see Table III) around 12:00 UTC, simultaneously with the ones at Bordeaux and Zaragoza.

Fig. 15 shows the vertical distributions of absolute humidity measured by HAMSTRAD-Tropo around 12:00-12:30 UTC on February 11-15 and 19-21, 2008 above PdM, together with radiosondes launched in Lannemezan, Zaragoza, and Bordeaux. Each day, only one HAMSTRAD-Tropo profile is considered. This represents an integration time of $\sim 7 \mathrm{~min}$. The retrieved profile was selected to be in the middle of the temporal window characterized by the time the Lannemezan sonde flies from the PdM altitude $(2877 \mathrm{~m})$ to $10 \mathrm{~km}$, namely, $\sim 20 \mathrm{~min}$. We have also calculated IWVs by integrating the $\mathrm{H}_{2} \mathrm{O}$ vertical profiles as measured by the different instruments above $2877-\mathrm{m}$ altitude. Note that the February 11-15 period can be considered as a dry period (IWVs $<1.5 \mathrm{~kg} \cdot \mathrm{m}^{-2}$ for all data sets except Zaragoza on February 14 and 15), while February 19-21 can be regarded as a climatologically standard winter period over PdM (IWVs $>3 \mathrm{~kg} \cdot \mathrm{m}^{-2}$ for all data sets). Considering the dry period, the vertical distribution of $\mathrm{H}_{2} \mathrm{O}$ above the altitude of PdM (namely, $2877 \mathrm{~m}$ ) does not exhibit large variabil-
TABLE III

DATES AND TIMES (UTC) OF RADIOSONDE LAUNCHES PERFORMED AT LANNEMEZAN

\begin{tabular}{cc}
\hline Date (YYYYMMDD) & Time (UTC) \\
\hline 20080211 & $12: 24$ \\
\hline 20080212 & $12: 07$ \\
\hline 20080213 & $12: 07$ \\
\hline 20080214 & $12: 01$ \\
\hline 20080215 & $11: 59$ \\
\hline 20080218 & $12: 01$ \\
\hline 20080219 & $12: 05$ \\
\hline 20080220 & $12: 00$ \\
\hline 20080221 & $12: 00$ \\
\hline 20080222 & $12: 00$ \\
\hline 20080303 & $12: 07$ \\
\hline 20080304 & $12: 08$ \\
\hline 20080305 & $11: 59$ \\
\hline 20080306 & $12: 02$ \\
\hline 20080307 & $12: 01$ \\
\hline 20080310 & $11: 59$ \\
\hline 20080311 & $12: 01$ \\
\hline 20080312 & $12: 05$ \\
\hline 20080313 & $10: 48$ \\
\hline 20080314 & $12: 00$ \\
\hline 20080319 & $12: 04$ \\
\hline 20080429 & $07: 52$ \\
\hline 20080429 & $12: 02$ \\
\hline
\end{tabular}

ity on February 11 and 12, showing a maximum of about $0.8-1.0 \mathrm{~g} \cdot \mathrm{m}^{-3}$ at the PdM altitude decreasing with height up to $8 \mathrm{~km}$ with a range of variation of $0.2-0.3 \mathrm{~g} \cdot \mathrm{m}^{-3}$. This is consistent with IWVs ranging from 0.57 to $1.53 \mathrm{~kg} \cdot \mathrm{m}^{-2}$ for all data sets. On February 13, the variability within the data sets is large above the PdM altitude, reaching about $0.5 \mathrm{~g} \cdot \mathrm{m}^{-3}$ with $\mathrm{H}_{2} \mathrm{O}$ dropping at $5 \mathrm{~km}$ (IWVs ranging from 0.95 to $1.86 \mathrm{~kg} \cdot \mathrm{m}^{-2}$ ). On February 14, the amount of $\mathrm{H}_{2} \mathrm{O}$ is extremely low (IWV $<1 \mathrm{~kg} \cdot \mathrm{m}^{-2}$ ) above PdM for all data sets except for Zaragoza $\left(3.72 \mathrm{~kg} \cdot \mathrm{m}^{-2}\right)$ with an interesting maximum in $\mathrm{H}_{2} \mathrm{O}$ measured by HAMSTRADTropo at $5 \mathrm{~km}$ consistent with the Zaragoza sounding, while Bordeaux and Lannemezan soundings are very consistent with each other, showing $0.2-0.3-\mathrm{g} \cdot \mathrm{m}^{-3}$ absolute humidity at PdM altitude decreasing with height. The absolute humidity observed during the extremely dry period is very similar to the $\mathrm{H}_{2} \mathrm{O}$ amounts above Dome C during summer seasons [24]. On February 15, the vertical distribution of $\mathrm{H}_{2} \mathrm{O}$ from HAMSTRAD-Tropo is ranging between Zaragoza soundings (upper bound) and Bordeaux-Lannemezan soundings (lower bound), with very dry atmosphere at PdM altitude in the Bordeaux soundings $\left(\sim 0.2 \mathrm{~g} \cdot \mathrm{m}^{-3}\right)$ and very wet in the Lannemezan and Zaragoza soundings $\left(\sim 2 \mathrm{~g} \cdot \mathrm{m}^{-3}\right)$, while HAMSTRAD-Tropo gives $\sim 1 \mathrm{~g} \cdot \mathrm{m}^{-3}$. This is reflected in the IWVs: Zaragoza $\left(\sim 3.5 \mathrm{~kg} \cdot \mathrm{m}^{-2}\right)$, Bordeaux and Lannemezan $\left(<1 \mathrm{~kg} \cdot \mathrm{m}^{-2}\right)$, and HAMSTRAD-Tropo $\left(\sim 1.5 \mathrm{~kg} \cdot \mathrm{m}^{-2}\right)$.

Considering a more climatological atmosphere (February 19-21), soundings and HAMSTRAD-Tropo retrievals of absolute humidity are somewhat more consistent with a weaker variability above the PdM altitude (0.1$0.4 \mathrm{~g} \cdot \mathrm{m}^{-3}$ ). On February 19, HAMSTRAD-Tropo retrieval and soundings from Bordeaux and Lannemezan are extremely consistent to each other (IWVs ranging from 5.47 to $5.70 \mathrm{~kg} \cdot \mathrm{m}^{-2}$ ), while on February $21, \mathrm{H}_{2} \mathrm{O}$ retrievals seem not to coincide with neither of the soundings (IWVs 

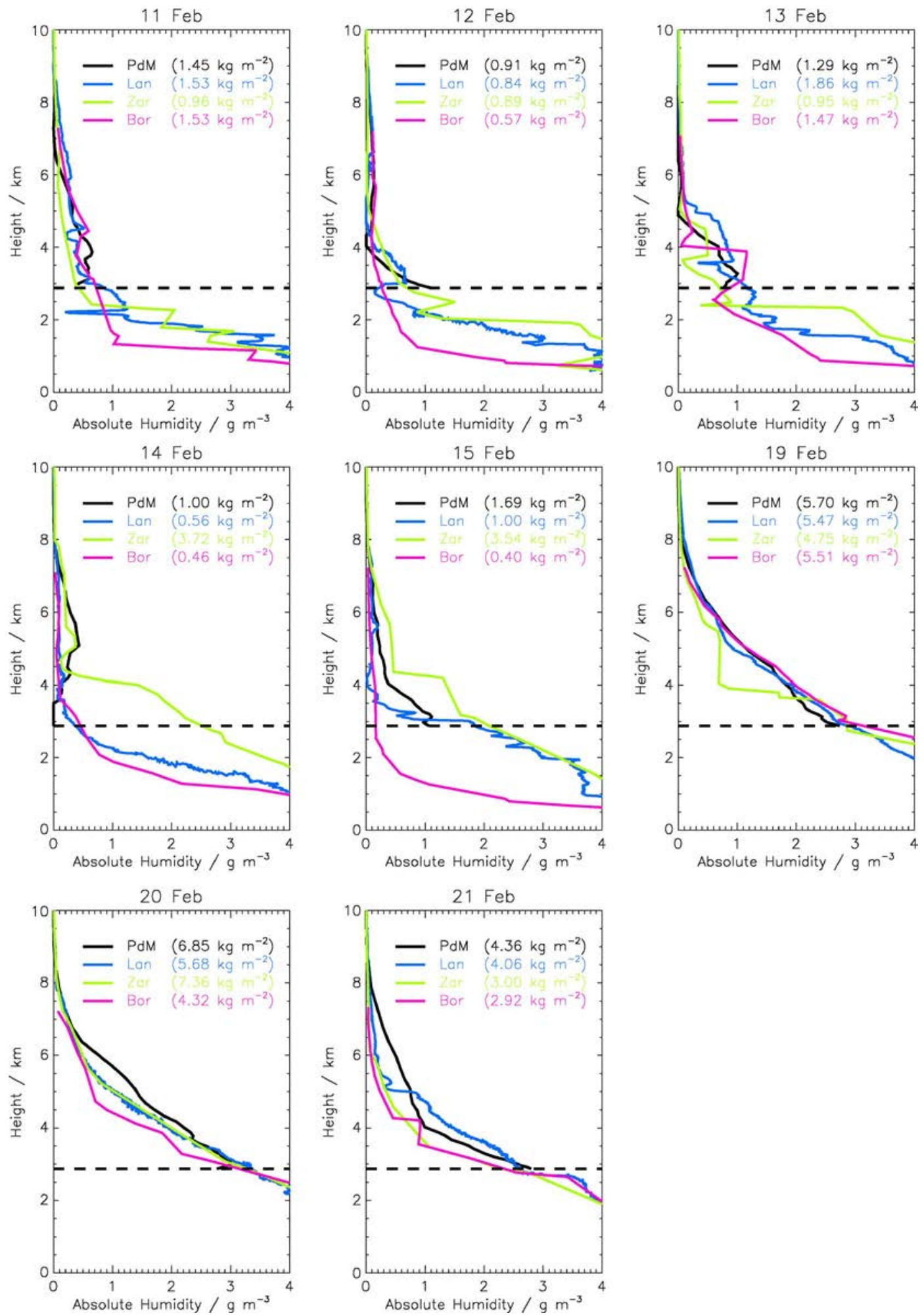

Fig. 15. Vertical distributions of the absolute humidity as measured by the (black line) HAMSTRAD-Tropo radiometer installed at the PdM and from the radiosondes launched at (blue line) Lannemezan, (red line) Bordeaux, and (green line) Zaragoza around 12:00-12:30 UTC on February 11, 12, 13, 14, 15, 19, 20, and 21,2008 . The horizontal dashed line represents the altitude of the PdM $(2877 \mathrm{~m})$. Also shown are the IWVs estimated from the vertical profiles of $\mathrm{H}_{2} \mathrm{O}$ as measured by the (black) HAMSTRAD-Tropo radiometer, and the sondes in (blue) Lannemezan, (green) Zaragoza, and (red) Bordeaux above $2877 \mathrm{~m}$.

ranging from 2.96 to $4.36 \mathrm{~kg} \cdot \mathrm{m}^{-2}$ ). We now consider the three HAMSTRAD-Tropo $\mathrm{H}_{2} \mathrm{O}$ retrievals (Fig. 16) on February 21 within the temporal width of $20 \mathrm{~min}$ that is roughly the time spent by the sonde to travel from 2877 - to 8000 -m altitudes. At 12:07 UTC, the sonde launched in Lannemezan is reaching the altitude of PdM, and the sonde profile is very consistent with HAMSTRAD-Tropo in the domain 2877-4500 m with an amount of $2.7 \mathrm{~g} \cdot \mathrm{m}^{-3}$ at $2877 \mathrm{~m}$. However, IWV from HAMSTRAD-Tropo $\left(5.05 \mathrm{~kg} \cdot \mathrm{m}^{-2}\right)$ is greater than IWV from Lannemezan sonde $\left(4.06 \mathrm{~kg} \cdot \mathrm{m}^{-2}\right)$. At 12:31 UTC, the sonde 

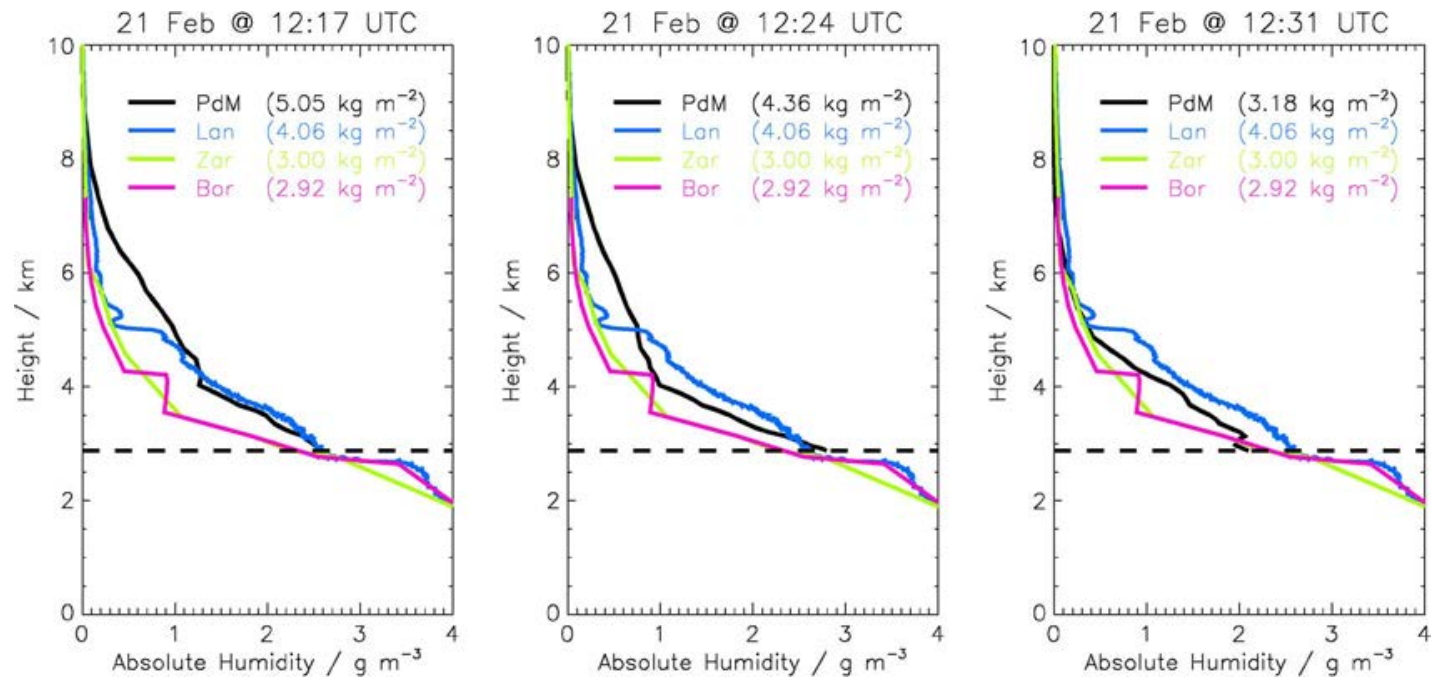

Fig. 16. $\mathrm{H}_{2} \mathrm{O}$ variability within 20 min on February 21, 2008, as measured by (black line) HAMSTRAD-Tropo at (left) 12:17 UTC, (center) 12:24 UTC, and (right) 12:31 UTC and from the sondes launched in (blue line) Lannemezan, (red line) Bordeaux, and (green line) Zaragoza. The Lannemezan sonde reaches the altitude of PdM $(2877 \mathrm{~m})$ at 12:07 UTC and the altitude of $8 \mathrm{~km}$ at 12:28 UTC. The horizontal dashed line represents the altitude of the PdM (2877 $\mathrm{m})$. Also shown are the IWVs estimated from the vertical profiles of $\mathrm{H}_{2} \mathrm{O}$ as measured by the (black) HAMSTRAD-Tropo radiometer, and the sondes in (blue) Lannemezan, (green) Zaragoza, and (red) Bordeaux above $2877 \mathrm{~m}$.

is reaching the altitude of $\sim 8 \mathrm{~km}$, and the sonde profile is very consistent with HAMSTRAD-Tropo in the domain 5000$8000 \mathrm{~m}$. In that case, IWV from HAMSTRAD-Tropo $\left(3.18 \mathrm{~kg} \cdot \mathrm{m}^{-2}\right)$ is less than IWV from Lannemezan sonde. In the intermediate time frame, at 12:24 UTC, HAMSTRADTropo retrievals obviously show two regimes with an inflexion point at 4000-m altitude and a vertical distribution inconsistent with the sonde profile. The IWV from HAMSTRAD-Tropo $\left(4.36 \mathrm{~kg} \cdot \mathrm{m}^{-2}\right)$ is very consistent with the IWV from Lannemezan sonde. There is thus a strong evidence that, because of its high time resolution, the temporal evolution of $\mathrm{H}_{2} \mathrm{O}$ profiles as deduced from HAMSTRAD-Tropo reflects the actual variability of the atmosphere. In order to check this assertion and because there is no coincident experimental data available over $24 \mathrm{~h}$ above the PdM site, we have made a case study on one particularly dry day by comparing the evolution of the absolute humidity as detected by HAMSTRAD-Tropo and as calculated by a state-of-the-art mesoscale model.

\section{B. Mesoscale Model}

In the following, measurements from HAMSTRADTropo were compared with a mesoscale simulation run on February 12, 2008, one of the days that experienced very dry conditions. The model is the nonhydrostatic mesoscale model MESO-NH [31], including, in particular, a 1.5-order turbulence scheme, an interactive radiation parameterization, and a prognostic microphysical scheme. The vertical grid length is set to $250 \mathrm{~m}$ in the free troposphere. Horizontal grid resolution is $32 \mathrm{~km}$. The simulation covers $2560 \times 2560 \mathrm{~km}^{2}$ over western Europe. It is integrated for $24 \mathrm{~h}$ starting with ECMWF analyses at 00:00 UTC February 12, 2008. Outputs from the nearest grid point of the PdM were kept every 5 min. The relatively coarse grid spacing of $32 \mathrm{~km}$ makes the nearest grid point located at a lower altitude than PdM (556 m against $2877 \mathrm{~m}$ ). It can lead to a poor representation of the local circulation such as slope winds that may affect the distribution of water vapor, but in the first hundred meters above PdM only.
Fig. 17 shows the daily evolution of the absolute humidity as measured by HAMSTRAD-Tropo and as calculated by MESO-NH on February 12, 2008, together with the IWV calculated from the vertical profiles above the PdM altitude. The date is particularly interesting to study because it corresponds to an extremely dry atmosphere (IWV $\sim 0.5 \mathrm{~kg} \cdot \mathrm{m}^{-2}$ for $2 \mathrm{~h}$ ) over PdM but with a relatively high variability reaching an IWV of $\sim 2 \mathrm{~kg} \cdot \mathrm{m}^{-2}$ at the end of the day. The LWP is very low $\left(<10 \mathrm{~g} \cdot \mathrm{m}^{-2}\right)$ over the entire day (Fig. 14), meaning that there are very few chances for clouds to have appeared except maybe high thin cirrus clouds. HAMSTRAD-Tropo shows indeed some absolute humidity of $\sim 1 \mathrm{~g} \cdot \mathrm{m}^{-3}$ confined within $1 \mathrm{~km}$ above PdM from 00:00 to 06:00 UTC, followed by a rapid decrease up to 09:00 UTC when the absolute humidity is only $0.1 \mathrm{~g} \cdot \mathrm{m}^{-3}$. Interestingly, a maximum in $\mathrm{H}_{2} \mathrm{O}$ of about $0.2-0.3 \mathrm{~g} \cdot \mathrm{m}^{-3}$ forms at $\sim 6000$-m altitude from 09:00 to 12:00. From 12:00, the absolute humidity at the PdM altitude starts increasing above $1 \mathrm{~g} \cdot \mathrm{m}^{-3}$ and propagates upward from 20:00 UTC, producing a local maximum at 5000-m altitude.

The temporal evolution of MESO-NH absolute humidity and IWV is very consistent with the measurements, since both data sets seem to track the same atmosphere in both absolute humidity and IWV, giving some more confidence in the reality of the rapid variability of $\mathrm{H}_{2} \mathrm{O}$ over PdM as measured by HAMSTRAD-Tropo. MESO-NH data set shows a lessening in $\mathrm{H}_{2} \mathrm{O}$ from 00:00 to 09:00 UTC and an increase from 12:00 to 24:00 UTC. Nevertheless, some slight differences are worth mentioning. At 09:00 UTC, a minimum in $\mathrm{H}_{2} \mathrm{O}$ is calculated at the PdM altitude but less intense than the measurements by $0.1 \mathrm{~g} \cdot \mathrm{m}^{-3}$, and two local maxima of 0.1 and $0.3 \mathrm{~g} \cdot \mathrm{m}^{-3}$ are modeled centered at 4000- and 8000-m altitudes, respectively, while one single maximum is observed at $\sim 6000-\mathrm{m}$ altitude. After 12:00 UTC, the amount of $\mathrm{H}_{2} \mathrm{O}$ increases in the model, producing a secondary maximum of $0.2 \mathrm{~g} \cdot \mathrm{m}^{-3}$ at $6000-\mathrm{m}$ altitude at 18:00 UTC very consistent with the measurements. After 20:00, the calculated humidity $\left(\sim 0.6 \mathrm{~g} \cdot \mathrm{m}^{-3}\right)$ is less than measured $\left(\sim 0.8 \mathrm{~g} \cdot \mathrm{m}^{-3}\right)$. Interestingly, if we consider the IWV field as calculated by MESO-NH but delayed by $2 \mathrm{~h}$, it almost 

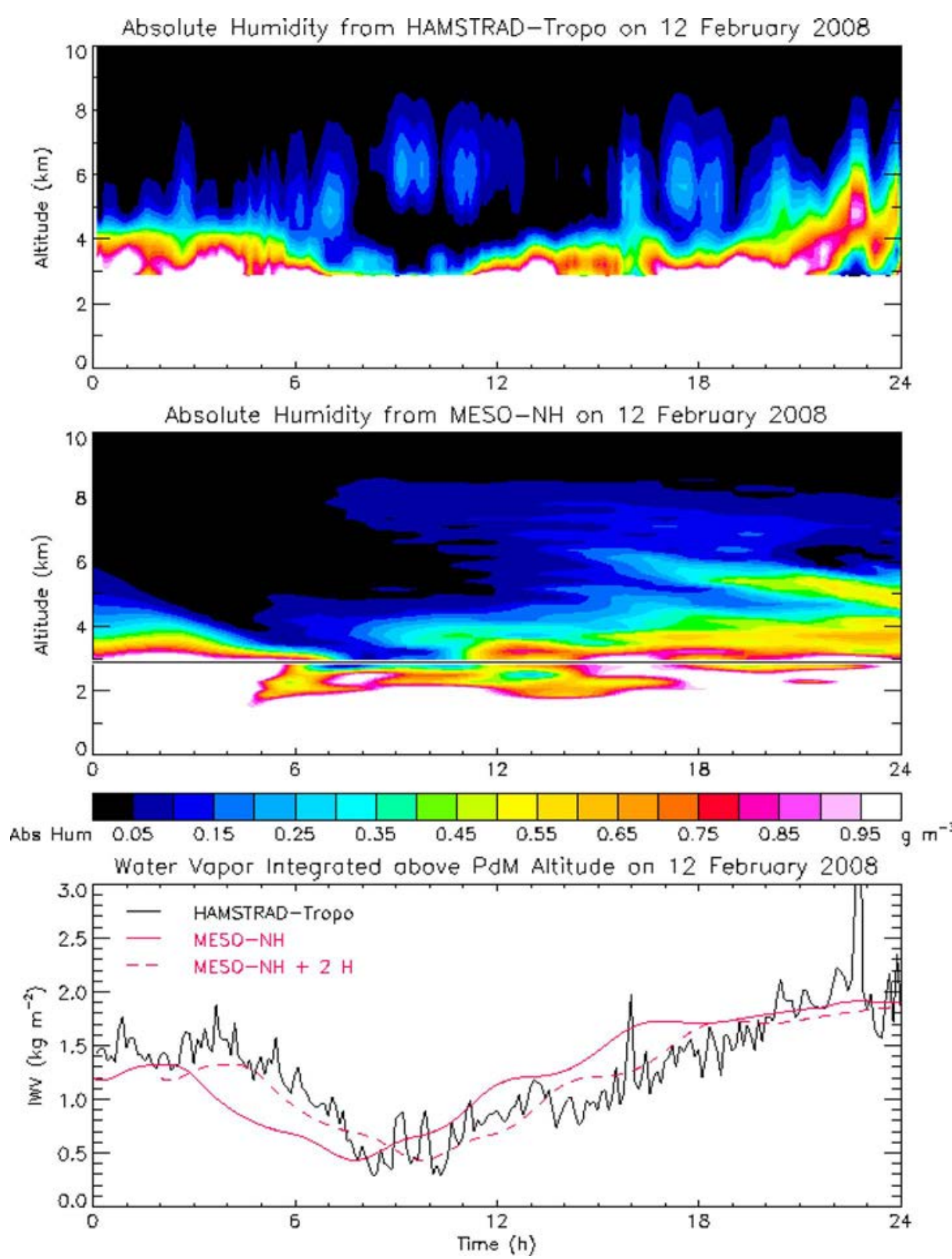

Fig. 17. (Top) HAMSTRAD-Tropo measurements and (middle) MESO-NH outputs of absolute humidity above PdM on February 12, 2008. The black horizontal line on the middle panel represents the altitude of the PdM. (Bottom) Diurnal evolution of IWV calculated from the vertical profiles of absolute humidity as measured by (black line) HAMSTRAD-Tropo and as calculated by (red line) MESO-NH and by (dashed red line) MESO-NH delayed by $2 \mathrm{~h}$ on February 12,2008 above the PdM altitude.

perfectly fits the IWV field as measured by HAMSTRADTropo. Furthermore, the differences between measured and modeled absolute humidity and IWV are likely to be attributed to local variations in the humidity fields that were not set in the initial conditions given by the analyses.

\section{CONCLUSION}

The HAMSTRAD-Tropo microwave radiometer has been developed for measuring tropospheric water vapor over Dome C, Antarctica, i.e., in an extremely dry and cold environment. It is a compact and fully automated instrument using state-of-the-art technology to be installed in a remote place and is intended to operate there over several years. It uses the spectral information contained in the domains $51-59 \mathrm{GHz}\left(\mathrm{O}_{2}\right.$ line $)$ and $168-197 \mathrm{GHz}\left(\mathrm{H}_{2} \mathrm{O}\right.$ line) to derive accurate tropospheric profiles of temperature and absolute humidity, together with IWV and LWP. It can use two observational modes: 1) a fulltroposphere mode, observing at zenith direction, to estimate profiles in the domain $0-10 \mathrm{~km}$ with a time resolution of $\sim 1 \mathrm{~min}$, and 2) a boundary-layer mode, scanning the atmosphere at different elevations, to get a better resolution and accuracy in the $0-2-\mathrm{km}$ vertical domain with a time resolution of $\sim 7 \mathrm{~min}$. For the Dome $\mathrm{C}$ station, the rms accuracies in the troposphere are the following: $1-2 \mathrm{~K}$ for temperature, $0.02-0.05 \mathrm{~g} \cdot \mathrm{m}^{-3}$ for absolute humidity, and $0.008 \mathrm{~kg} \cdot \mathrm{m}^{-2}$ for IWV.

The HAMSTRAD-Tropo radiometer has been installed at the PdM site (2877 m asml) in the French Pyrénées Mountains in February 2008 until June 2008. Preliminary comparisons 
performed in February 2008 against radiosondes particularly launched in the vicinity of $\mathrm{PdM}$ and against the mesoscale MESO-NH model are very promising. First, whatever the atmosphere considered over PdM (extremely dry as it can be encountered at Dome $\mathrm{C}$ in summer season or wet in accordance to the climatology of the site), the absolute humidity profiles estimated by HAMSTRAD-Tropo are very consistent with the external sources of data (sondes and model) to within 0.2$0.3 \mathrm{~g} \cdot \mathrm{m}^{-3}$. Second, the extreme variability (even on very short period time frames of $\sim 20 \mathrm{~min}$ ) of the measured absolute humidity is also calculated by the model. This means that the HAMSTRAD-Tropo radiometer is stable and precise enough to detect weak and rapid changes in the actual atmosphere. A complete validation of the HAMSTRAD-Tropo $\mathrm{H}_{2} \mathrm{O}$ measurements against sonde, satellite, and model data is presented in [28]. The radiometer has been installed at Dome C in January 2009, and preliminary results will be shown in [29].

\section{ACKNOWLEDGMENT}

The authors would like to thank their colleagues from the Observatoire du Pic du Midi (namely, O. Drasin, E. Motte, M. Niclas, F. Lacaze, and S. Rigobert at the Laboratoire d'Aérologie, together with the technical staff at PdM) for their helpful support at different stages of the HAMSTRAD Programme. The HAMSTRAD program has been funded by the Institut National des Sciences de l'Univers/Centre National de la Recherche Scientifique. The HAMSTRAD-Tropo radiometer has been scientifically approved by the Institut Paul Emile Victor for an installation at the Dome C station in Antarctica over the 2008-2009 austral summer.

\section{REFERENCES}

[1] World Meteorological Organization, Scientific Assessment of Ozone Depletion: 2006. Geneva, Switzerland: WMO, 2006.

[2] M. Scherer, H. Vömel, S. Fueglistaler, S. J. Oltmans, and J. Staehelin, "Trends and variability of midlatitude stratospheric water vapour deduced from the re-evaluated Boulder balloon series and HALOE," Atmos. Chem. Phys., vol. 8, no. 5, pp. 1391-1402, 2008.

[3] G. P. Brasseur, J. J. Orlando, and G. S. Tyndall, Atmospheric Chemistry and Global Change, 2nd ed. New York: Oxford Univ. Press, 1999.

[4] J. A. Pyle, N. R. P. Harris, J. C. Farman, F. Arnold, G. Braathen, R. A. Cox, P. Faucon, R. L. Jones, G. Megie, A. O'Neill, U. Platt, J.-P. Pommereau, U. Schmidt, and F. Stordal, "An overview of the EASOE campaign," Geophys. Res. Lett., vol. 21, no. 13, pp. 1191-1194, 1994.

[5] E. Motte, P. Ricaud, B. Gabard, M. Niclas, and F. Gangneron, "A $22 \mathrm{GHz}$ mobile microwave radiometer (MobRa) for the study of stratospheric water vapor," IEEE Trans. Geosci. Remote Sens., vol. 46, no. 10, pp. 31043114, Oct. 2008.

[6] J.-P. Pommereau and F. Goutail, "O3 and NO2 ground-based measurements by visible spectrometry during arctic winter and spring 1988," Geophys. Res. Lett., vol. 15, no. 8, pp. 891-894, 1988.

[7] A. F. Bais, B. G. Gardiner, H. Slaper, M. Blumthaler, G. Bernhard, R. McKenzie, A. R. Webb, G. Seckmeyer, B. Kjeldstad, T. Koskela, P. J. Kirsch, J. Gröbner, J. B. Kerr, S. Kazadzis, K. Leszczynski, D. Wardle, W. Josefsson, C. Brogniez, D. Gillotay, H. Reinen, P. Weihs, T. Svenoe, P. Eriksen, F. Kuik, and A. Redondas, "SUSPEN intercomparison of ultraviolet spectroradiometers," J. Geophys. Res., vol. 106, no. D12, pp. 12 509-12 525, 2001.

[8] NDACC web site, 2007. [Online]. Available: http://www.ndsc.ncep. noaa.gov

[9] D. Murtagh, U. Frisk, F. Merino, M. Ridal, A. Jonsson, J. Stegman, G. Witt, P. Eriksson, C. Jiménez, G. Megie, J. De La Noë, P. Ricaud, P. Baron, J. R. Pardo, A. Hauchcorne, E. J. Llewellyn, D. A. Degenstein, R. L. Gattinger, N. D. Lloyd, W. F. J. Evans, I. C. McDade, C. S. Haley, C. Sioris, C. Von Savigny, B. H. Solheim, J. C. McConnell, K. Strong,
E. H. Richardson, G. W. Leppelmeier, E. Kyrölä, H. Auvinen, and L. Oikarinen, "Review: An overview of the Odin mission," Can. J. Phys., vol. 80, pp. 309-319, Apr. 2002.

[10] B. Carli, D. Alpaslan, M. Carlotti, E. Castelli, S. Ceccherini, B. M. Dinelli, A. Dudhia, J. M. Flaud, M. Hoepfner, V. Jay, L. Magnani, H. Oelhaf, V. Payne, C. Piccolo, M. Prosperi, P. Raspollini, J. Remedios, M. Ridolfi, and R. Spang, "First results of MIPAS/ENVISAT with operational level 2 code," Adv. Space Res., vol. 33, no. 7, pp. 1012-1019, 2004.

[11] L. Froidevaux, N. J. Livesey, W. G. Read, Y. B. Jiang, C. Jimenez, M. J. Filipiak, M. J. Schwartz, M. L. Santee, H. C. Pumphrey, J. H. Jiang, D. L. Wu, G. L. Manney, B. J. Drouin, J. W. Waters, E. J. Fetzer, P. F. Bemath, C. D. Boone, K. A. Walker, K. W. Jucks, G. C. Toon, J. J. Margitan, B. Sen, C. R. Webster, L. E. Christensen, J. W. Elkins, E. Atlas, R. A. Lueb, and R. Hendershot, "Early validation analyses of atmospheric profiles from EOS MLS on the Aura satellite," IEEE Trans. Geosci. Remote Sens., vol. 44, no. 5, pp. 1106-1121, May 2006.

[12] J. A. Lerner, E. Weisz, and G. Kirchengast, "Temperature and humidity retrieval from simulated Infrared Atmospheric Sounding Interferometer (IASI) measurements," J. Geophys. Res., vol. 107, no. D14, p. 4189, Jul. 2002. DOI: 10.1029/2001JD900254.

[13] G. Nedoluha, R. M. Bevilacqua, R. M. Gomez, D. L. Thacker, W. B. Waltman, and T. A. Pauls, "Ground-based measurements of water vapor in the middle atmosphere," J. Geophys. Res., vol. 100, no. D2, pp. 2927-2939, Feb. 1995

[14] P. Forkman, P. Eriksson, and A. Winnberg, "The 22 GHz radio-aeronomy receiver at Onsala Space Observatory," J. Quant. Spec. Radiat. Transf., vol. 77 , no. 1, pp. 23-42, 2003.

[15] A. L. Pazmany, "A compact $183-\mathrm{GHz}$ radiometer for water vapor and liquid water sensing," IEEE Trans. Geosci. Remote Sens., vol. 45, no. 7, pp. 2202-2206, Jul. 2007.

[16] D. Cimini, E. R. Westwater, A. J. Gasiewski, M. Klein, V. Y. Leuski, and J. C. Liljegren, "Ground-based millimeter- and submillimeter-wave observations of low vapor and liquid contents," IEEE Trans. Geosci. Remote Sens., vol. 45, no. 7, pp. 2169-2180, Jul. 2007.

[17] E. R. Westwater, D. Cimini, V. Mattioli, A. Gasiewski, M. Klein, V. Leuski, and J. Liljegren, "The 2004 North slope of Alaska Arctic winter radiometric experiment: Overview and highlights," in Proc. Microw. Spec. Meeting, San Juan, Puerto Rico, 2006, pp. 77-81.

[18] D. Cimini, E. R. Westwater, A. J. Gasiewski, M. Klein, V. Y. Leuski, and S. Dowlatshabi, "The ground-based scanning radiometre: A powerful tool for study of the Arctic atmosphere," IEEE Trans. Geosci. Remote Sens., vol. 45, no. 9, pp. 2759-2777, Sep. 2007.

[19] P. E. Racette, E. R. Westwater, Y. Han, A. Gasiewski, M. Klein, D. Cimini, W. Manning, E. Kim, J. Wang, and P. Kiedron, "Measurement of low amounts of precipitable water vapor using ground-based millimeterwave radiometry," J. Atmos. Ocean. Technol., vol. 22, no. 4, pp. 317-337, Apr. 2005.

[20] V. Mattioli, E. R. Westwater, D. Cimini, A. J. Gasiewski, M. Klein, and V. Y. Leuski, "Microwave and millimeter-wave radiometric and radiosonde observations in an arctic environment," J. Atmos. Ocean. Technol., vol. 25, no. 10, pp. 1768-1777, 2008.

[21] V. Mattioli, E. R. Westwater, D. Cimini, J. S. Liljegren, B. M. Lesht, S. I. Gutman, and F. J. Schmidlin, "Analysis of radiosonde and groundbased remotely sensed PWV data from the 2004 North slope of Alaska Arctic winter radiometric experiment," J. Atmos. Ocean. Technol., vol. 24, no. 3, pp. 415-431, Mar. 2007.

[22] H. J. Liebe, "MPM, An atmospheric millimeter-wave propagation model," Int. J. Infrared Millim. Waves, vol. 10, no. 6, pp. 631-650, 1989.

[23] P. W. Rosenkranz, "Water vapor microwave continuum absorption: A comparison of measurements and models," Radio Sci., vol. 33, no. 4, pp. 919-928, 1998.

[24] C. Tomasi, B. Petkov, E. Benedetti, V. Vitale, A. Pellegrini, G. Dargaud, L. De Silvestri, P. Grigioni, E. Fossat, W. L. Roth, and L. Valenziano, "Characterization of the atmospheric temperature and moisture conditions above Dome C (Antarctica) during austral summer and fall months," J. Geophys. Res., vol. 111, no. D20, p. D20 305, 2006. DOI:10.1029/2005JD006976.

[25] S. Crewell and U. Löhnert, "Accuracy of boundary layer temperature profiles retrieved with multi-frequency, multi-angle microwave radiometry," IEEE Trans. Geosci. Remote Sens., vol. 45, no. 7, pp. 2195-2201, Jul. 2007.

[26] G. Backus and F. Gilbert, "Uniqueness in the inversion of inaccurate gross Earth data," Philos. Trans. R. Soc. London, vol. 266, no. 1173, pp. 123-192, 1970

[27] C. D. Rodgers, Inverse Methods for Atmospheric Sounding: Theory and Practice, 1st ed. River Edge, NJ: World Scientific, 2000. 
[28] P. Ricaud, O. Drasin, B. Gabard, S. Derrien, J.-L. Attié, T. Rose, and H. Czekala, "Validation of tropospheric water vapour as measured by the 183-GHz radiometer HAMSTRAD-Tropo over the Pyrenees Mountains, France," IEEE Trans. Geosci. Remote Sens., 2009, submitted for publication.

[29] P. Ricaud, B. Gabard, O. Drasin, S. Derrien, J.-P. Chaboureau, J.-L. Attié, T. Rose, A. Mombauer, and H. Czekala, "The 183-GHz HAMSTRADtropo radiometer: Validation over the Pyrenees Mountains (France) and first measurements at Dome C (Antarctica)," in Proc. IEEE IGARSS Conf., Cape Town, South Africa, Jul. 13-17, 2009. [CD-ROM].

[30] A. Chevalier, F. Gheusi, R. Delmas, C. Ordóñez, C. Sarrat, R. Zbinden, V. Thouret, G. Athier, and J.-M. Cousin, "Influence of altitude on ozone levels and variability in the lower troposphere: A ground-based study for western Europe over the period 2001-2004," Atmos. Chem. Phys., vol. 7, no. 16, pp. 4311-4326, 2007.

[31] J. P. Lafore, J. Stein, N. Asencio, P. Bougeault, V. Ducrocq, J. Duron, C. Fischer, P. Hereil, P. Mascart, J. P. Pinty, J. L. Redelsperger, E. Richard, and J. Vila-Guerau de Arellano, "The Meso-NH atmospheric simulation system. Part I: Adiabatic formulation and control simulations," Ann. Geophys., vol. 16, no. 1, pp. 90-109, 1998. 